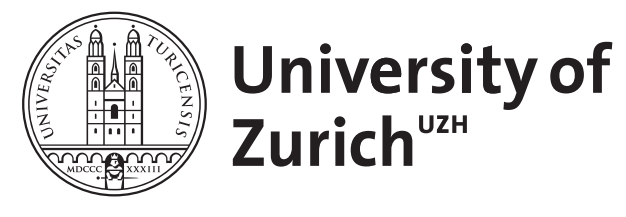

\title{
Imaging chemical reactions one molecule at a time
}

\author{
Novotny, Z ; Zhang, Z ; Dohnálek, Z
}

\begin{abstract}
In this article, we focus on demonstrating the utility of scanning probe methods in the imaging of chemical reactions. We first highlight the utility of different imaging methods and highlight their advantages and drawbacks. Subsequently, we select a number of examples to illustrate different surface processes including adsorption, dissociation, diffusion and rotation of adsorbed molecules, formation of reaction intermediates, and conclude with complex reactions. In these examples, we mainly focus on the STM, which is most extensively employed as a method of choice. To limit the complexity of the article we have selected only a few systems for the discussion. In particular, elemental steps in the reactions of water, alcohols, and diols on $\mathrm{TiO} 2(110)$ surface are utilized to illustrate the power of imaging techniques in our understanding of surface chemistry. We also provide a brief outlook on both current and future challenges in this exciting area of research.
\end{abstract}

DOI: https://doi.org/10.1016/B978-0-12-409547-2.12844-6

Posted at the Zurich Open Repository and Archive, University of Zurich

ZORA URL: https://doi.org/10.5167/uzh-142471

Book Section

Accepted Version

Originally published at:

Novotny, Z; Zhang, Z; Dohnálek, Z (2018). Imaging chemical reactions one molecule at a time. In: Wandelt, Klaus. Encyclopedia of interfacial chemistry : surface science and electrochemistry. Amsterdam: Elsevier, 220-240.

DOI: https://doi.org/10.1016/B978-0-12-409547-2.12844-6 


\section{AUTHOR QUERY FORM}

\begin{tabular}{|c|c|c|}
\hline 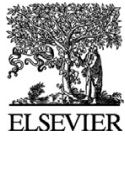 & $\begin{array}{l}\text { Book: Encyclopedia of Interfacial } \\
\text { Chemistry: Surface Science and } \\
\text { Electrochemistry } \\
\text { Chapter: } 12844\end{array}$ & $\begin{array}{l}\text { Please e-mail your responses and any } \\
\text { corrections to: } \\
\text { E-mail: mrw-ifce@elsevier.com }\end{array}$ \\
\hline
\end{tabular}

Dear Author,

Any queries or remarks that have arisen during the processing of your manuscript are listed below and are highlighted by flags in the proof. (Q indicates author queries; ED indicates editor queries.) Please check your proof carefully and answer all Q queries. Mark all corrections and query answers at the appropriate place in the proof (e.g., by using on-screen annotation in the PDF file http:/www.elsevier.com/book-authors/science-and-technology-book-publishing/overviewof-the-publishing-process) or compile them in a separate list, and tick off below to indicate that you have answered the query.

Please return your input as instructed by the project manager.

\begin{tabular}{|l|l|}
\hline Location in Chapter & Query / remark \\
\hline Q:1, page 19 & $\begin{array}{l}\text { Please provide the corresponding grant number(s) for the following } \\
\text { grant sponsor(s): "National Science Foundation" and "Basic Energy } \\
\text { Sciences". }\end{array}$ \\
\hline Q:2, page 13 & Please check and confirm the inserted citation of Fig. 17. \\
\hline Q:3, page 14 & Please check the sentence "These reactions parallel..." for clarity. \\
\hline
\end{tabular}




\section{IFCC: 12844}

$\mathrm{a} 0010$

$$
\text { I }
$$

\section{Z Novotny, University of Zürich, Zürich, Switzerland}

Z Zhang, Baylor University, Waco, TX, United States

DohnalekZ Dohnálek, Pacific Northwest National Laboratory, Richland, WA, United states; Washington State University, Pullman, WA, United States

(C) 2017 Elsevier Inc. All rights reserved.

\begin{tabular}{|c|c|}
\hline Introduction & 2 \\
\hline Basics of Scanning Probe Techniques & 2 \\
\hline Scanning Tunneling Microscopy & 3 \\
\hline Atomic Force Microscopy & 3 \\
\hline Benefits and Drawbacks of Single Molecule Imaging by STM & 3 \\
\hline Reagent Delivery & 4 \\
\hline Imaging Elemental Steps in Surface Reactions & 5 \\
\hline Molecular Adsorption & 5 \\
\hline Same area imaging & 7 \\
\hline Bias- and tunneling current-dependent imaging & 7 \\
\hline Scanning tunneling spectroscopy & 8 \\
\hline Tip-induced manipulations & 8 \\
\hline Simulation of STM images & 9 \\
\hline Inelastic electron tunneling spectroscopy & 10 \\
\hline Adsorbate Motion & 11 \\
\hline Rotational dynamics & 11 \\
\hline Surface diffusion & 13 \\
\hline Formation of Surface Intermediates & 14 \\
\hline Imaging Complex Reactions & 16 \\
\hline Future Directions and Challenges & 17 \\
\hline High Pressure and Condensed Phase Studies & 17 \\
\hline Combined molecular beam scattering and scanning tunneling microscopy & 17 \\
\hline Adsorbate Structure Imaging with Functionalized Scanning Probes & 18 \\
\hline Combining Scanning Probe Techniques with Vibrational Spectroscopies & 18 \\
\hline References & 20 \\
\hline
\end{tabular}

\begin{tabular}{|c|c|c|c|c|c|}
\hline & Nomenclature & & $\mathrm{Ti}_{\mathrm{c}}$ & 5-Fold coordinated surface titanium cation & dt0085 \\
\hline & General Abbrev & iations & Ti6 $_{\mathrm{c}}$ & 6-Fold coordinated surface titanium cation & dt0090 \\
\hline dt0010 & $\mathrm{DO}_{\mathrm{b}}$ & Deuterated bridging hydroxyl-deuterium & $\begin{array}{l}\text { vdW } \\
V_{G}\end{array}$ & $\begin{array}{l}\text { Van der Waals } \\
\text { Gap voltage, tunneling bias }\end{array}$ & $\begin{array}{l}\text { dt0095 } \\
\text { dt0100 }\end{array}$ \\
\hline dt0015 & $\mathrm{DO}_{\mathrm{t}}$ & $\begin{array}{l}\text { bonded on top of } \mathrm{O}_{\mathrm{b}} \\
\text { Deuterated terminal hydroxyl-OD on top } \\
\text { of Ti5 } 5_{\mathrm{c}}\end{array}$ & $\mathrm{V}_{\mathbf{O}}$ & Bridging oxygen vacancy & dt0105 \\
\hline dt0020 & Н2ТВРP & $\begin{array}{l}\text { Meso-tetrakis(3,5-di-tertiarybutylphenyl)- } \\
\text { porphyrin }\end{array}$ & $\begin{array}{l}\text { Abbreviations } \\
\text { AES }\end{array}$ & Auger electron spectroscopy & dt0110 \\
\hline dt0025 & $\mathrm{HO}_{\mathrm{b}}$ & $\begin{array}{l}\text { Bridging hydroxyl-hydrogen bonded on } \\
\text { top of } \mathrm{O}_{\mathrm{b}}\end{array}$ & $\begin{array}{l}\text { AFM } \\
\text { AIMD }\end{array}$ & $\begin{array}{l}\text { Atomic force microscopy } \\
\mathrm{Ab} \text { initio molecular dynamics }\end{array}$ & $\begin{array}{l}\text { dt0115 } \\
\text { dt0120 }\end{array}$ \\
\hline dt0030 & $\mathrm{HO}_{\mathrm{t}}$ & Terminal hydroxyl-OH on top of $\mathrm{Ti} 5_{\mathrm{c}}$ & DFT & Density functional theory & dt0125 \\
\hline dt0035 & $\mathbf{I}_{\mathrm{HT}}$ & High-temperature intermediate & DOS & Density of states & dt0130 \\
\hline dt0040 & $I_{t}$ & Tunneling current & IETS & Inelastic electron tunneling spectroscopy & dt0135 \\
\hline dt0045 & ML & Monolayer & IR & Infrared & dt0140 \\
\hline dt0050 & $\mathrm{O}_{\mathrm{a}}$ & Oxygen adatom-O bonded on top of $\mathrm{Ti} 5_{\mathrm{c}}$ & IRRAS & Infrared reflection absorption spectroscopy & dt0145 \\
\hline dt0055 & $\mathrm{O}_{\mathrm{b}}$ & Bridging oxygen & MD & Molecular dynamics & dt0150 \\
\hline dt0060 & $\mathrm{Ob}\left(\mathrm{CH}_{2}\right)$ & Dioxy species bound on $\mathrm{O}_{\mathrm{b}}$ and $\mathrm{Ti} 5_{\mathrm{c}}$ sites & SNOM & Scanning near-field optical microscopy & dt0155 \\
\hline dt0065 & $\mathrm{Ob}\left(\mathrm{CH}_{2}\right) \mathrm{nOH}$ & Hydroalkoxy species bound on $\mathrm{O}_{\mathrm{b}}$ site & SPM & Scanning probe microscopy & dt0160 \\
\hline dt0070 & PS-b-PMMA & Poly(styrene-block-methyl methacrylate) & STM & Scanning tunneling microscopy & dt0165 \\
\hline dt0075 & $\mathrm{RO}_{\mathrm{b}}$ & Bridging alkoxy - alkyl group bonded on & STS & Scanning tunneling spectroscopy & dt0170 \\
\hline & & $\mathrm{O}_{\mathrm{b}}$ & TERS & Tip-enhanced Raman spectroscopy & dt0175 \\
\hline dt0080 & ROH & Alcohol & TPD & Temperature programed desorption & dt0180 \\
\hline
\end{tabular}




\section{IFCC: 12844}

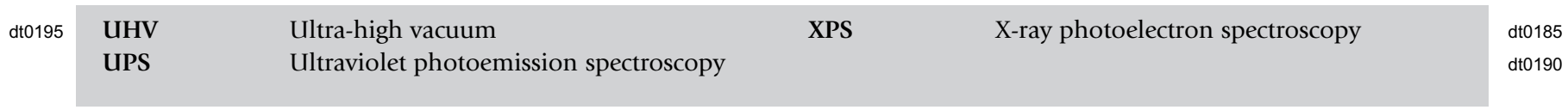

\section{s0015 Introduction}

p0205 The invention of scanning tunneling microscopy (STM) ${ }^{1}$ changed our atomistic understanding of surface processes in a revolutionary way and allowed for unprecedented progress in many areas of science. Seeing structural motifs in real space allowed us to determine the configuration of atoms on complex surfaces and identify and quantify various structural defects such as dislocations, steps, missing or added atoms, and impurities. Now famous, the first STM image of Si(111) surface (Fig. 1A) from 1983 resolved its complex $(7 \times 7)$ reconstruction ${ }^{2}$ and earned Rohrer and Binnig Nobel Prize in Physics in 1986. Currently, many flavors of scanning probe methods exist and employ a variety of tip-surface interactions to generate space-resolved maps of surface properties that include conductivity, electrostatic and van der Waals interactions, magnetization, spin, hydrophilicity, work function, and others. ${ }^{3}$ However, the scanning probe methods are nowadays not only employed as simply imaging techniques. They can provide information about the local electronic and vibrational structure of the imaged features, the tip functionalization with molecules is used to enhance resolution and to obtain specific information about physical and chemical properties at the atomic scale, and the tip manipulation can be employed to assemble nanostructures with atomic precision and to induce local reactions. The list of processes that can be followed with modern scanning probes is practically endless.

p0210 In this review, we focus on demonstrating the utility of the scanning probe methods in one specific area, imaging of the chemical reactions. While the surface reactions are critical in many different areas such as materials science, geoscience, electrochemistry, corrosion, precipitation and dissolution, tribology, and others, heterogeneous catalysis represents a prime example where understanding the role catalysts' make-up and structure play in determining the rates and selectivity of the product formation is essential. The speedy progress from the imaging of bare surfaces to adsorbates and reactions is illustrated in Fig. 1 (Refs. 2,4,5).

p0215 In this review, we first illustrate the utility of different imaging schemes and highlight their strengths and weaknesses (Section "Basics of Scanning Probe Techniques"). Subsequently, we select a number of examples to illustrate different surface processes including adsorption, dissociation, diffusion and rotation of adsorbed molecules, formation of reaction intermediates, and conclude this section (Section "Imaging Elemental Steps in Surface Reactions") with complex reactions. In these examples, we mainly focus on the STM, which is most extensively employed as a method of choice. To limit the complexity of the article we have selected only a few systems for the discussion. In particular, elemental steps in the reactions of water, alcohols, and diols on $\mathrm{TiO}_{2}(110)$ surface are utilized to illustrate the power of imaging techniques in our understanding of surface chemistry. In the last part (Section "Future Directions and Challenges"), we provide a brief outlook on both current and future challenges in this exciting area of research.

\section{s0020 Basics of Scanning Probe Techniques}

p0220 Shortly after the introduction of STM, ${ }^{6}$ many variations quickly followed. ${ }^{3,7}$ The techniques are now commonly referred to as scanning probe microscopies (SPM), as they all rely on the probe scanning in the proximity of the surface. The key difference among various SPM methods is the type of probe-sample interaction (signal) being measured. We have selected two most popular methods used in the imaging of surface reactions: STM and atomic force microscopy (AFM) and briefly introduce both below (Fig. 2). For further details, the reader is referred to numerous books and review articles in the literature. . $^{3,7}$

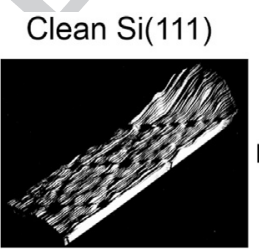

Published:1983

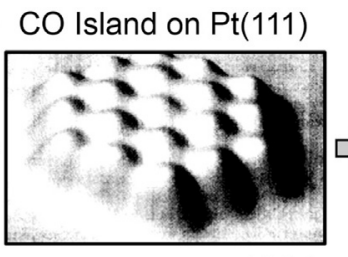

1991

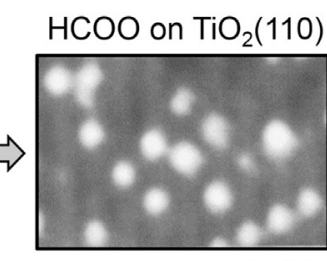

1994

Fig. 1 A timeline illustrating the progression of imaging from clean surfaces to adsorbates and reactions. (A) One of the first STM images illustrates $7 \times 7$ reconstruction of $\mathrm{Si}(111)$ (Reproduced with permission from Binnig, G.; Rohrer, H.; Gerber, C.; Weibel, E. $7 \times 7$ Reconstruction on Si(111) Resolved in Real Space. Phys. Rev. Lett. 1983, 50, 120-123). (B) An example of early study of molecularly adsorbed CO island on Pt(111) (Reproduced with permission from Stroscio, J. A.; Eigler, D. M., Atomic and Molecular Manipulation with the Scanning Tunneling Microscope. Science 1991, 254 , 1319-1326). (C) One of the earliest studies where STM was used to study chemical reactions on metal oxide surfaces. Here $\mathrm{TiO}_{2}(110)$ (used as a primary model system throughout this review) was exposed to formic acid and the formate intermediates and their diffusion was imaged.Adapted with permission from Onishi, H.; Iwasawa, Y. STM Imaging of Formate Intermediates Adsorbed on a $\mathrm{TiO}_{2}(110)$ surface. Chem. Phys. Lett. 1994, 226, $111-114$. 


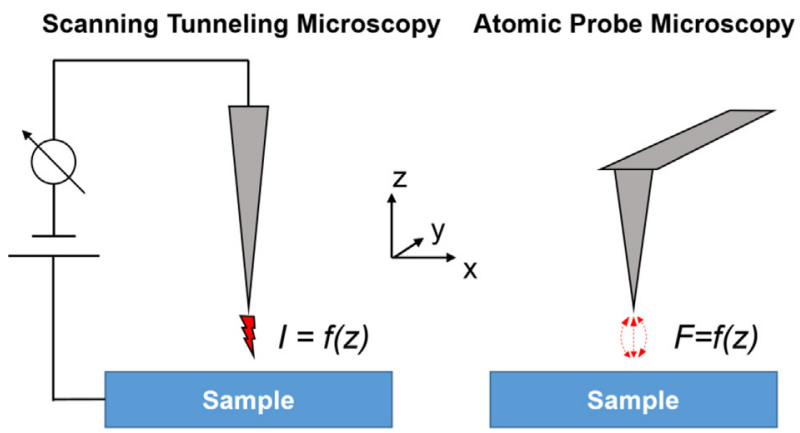

Fig. 2 Schematic view of two SPM techniques (STM and AFM) most commonly employed in the studies of adsorbates on surfaces.

\section{s0025 Scanning Tunneling Microscopy}

p0225 Scanning tunneling microscopy, the original SPM technique, relies on probing the local electronic density of states at the surface. The image contrast is based on electron tunneling through a controllable gap, ${ }^{1}$ with a bias voltage, $V_{\mathrm{G}}$, applied between the sample and the sharp metallic tip (usually made from tungsten). This technique utilizes a decay of the tip and sample wavefunctions into the vacuum and their overlap within very short distances $(\sim 1 \mathrm{~nm})$. The range of states below (filled) and above (empty) the Fermi level is sampled by setting a negative or positive sample bias, respectively. Tunneling current, $I_{\mathrm{t}}$, depends exponentially on the distance between the sample and the tip, $z$, and the measured tunneling current is used as a reference signal for the $z$-feedback loop. While the STM is the most commonly used SPM technique, its applications are limited to samples with sufficient surface electrical conductivity, leaving a broad class of insulating materials inaccessible.

p0230 Traditionally, STM is used in the topographic mode, where the tip is scanning in the $x y$ plane while keeping the tunneling current constant and recording the $z$ position. In the second imaging mode, a constant height mode, the feedback loop is disabled, and scanning is performed at a constant height $z$. The recorded variation in the tunneling current then reflects the atomic structure of the surface.

p0235 The great advantage of STM for the reactivity studies is that it can operate in a broad range of temperatures ( $\mathrm{mK}$ to $1000 \mathrm{~K}$ ) and pressures. The high-pressure/high-temperature STM instruments are typically contained within a high-pressure cell to limit the exposure of the whole UHV system to the reactants and have been termed reactorSTM..$^{8,9}$

\section{s0030 Atomic Force Microscopy}

p0240 The development of the AFM extended the SPM capability to nonconductive samples. ${ }^{10,11}$ The imaging mechanism is based on the measurement of attractive/repulsive forces (van der Waals, electrostatic, etc.) between the tip and the sample. The tip is mounted on a cantilever that works as a spring and allows to be used as a force detector. The cantilever is rigid along the $x$ - and $y$-axis while being relatively soft along the $z$-axis.

p0245 AFM can be used in a number of modes, but for imaging of adsorbates, a noncontact mode is the most appropriate. In this dynamic mode the cantilever vibrates with a frequency modulation of the force sensor that is similar to the timekeeping element in modern watches. Such quartz tuning fork (qPlus) sensors provide an excellent frequency stability over time and temperature variations with little energy consumption.

p0250 AFM is inherently more complex than STM, and it took almost 10 years since its invention before the atomic resolution on reactive surfaces was achieved. ${ }^{10}$ Even now AFM is rarely used to study chemical reactions. In contrast with STM, in AFM, the force between the sample and the tip has both short- and long-range components. This force is not monotonic, being attractive for large tip-sample distances, and repulsive for short tip-sample distances, making an establishment of a stable $z$-feedback loop more complex. In addition, since the sum of the overall tip to sample forces is measured, the source of atomic resolution is often hard to identify. In recent years, chemically functionalized tips operated at cryogenic temperatures became popular in many groups. A CO molecule is typically used to image adsorbates with submolecular resolution. This high resolution is attributed to Pauli repulsion between the CO molecule and the probed molecule on the surface (see Section "Adsorbate Structure Imaging with Functionalized Scanning Probes" $).{ }^{12}$

\section{s0035 Benefits and Drawbacks of Single Molecule Imaging by STM}

p0255 Since the STM is by far the most commonly used SPM technique and its examples are used extensively throughout this review, we briefly summarize its strengths and weaknesses as compared to ensemble average techniques that are typically employed in the reactivity studies. 


\section{IFCC: 12844}

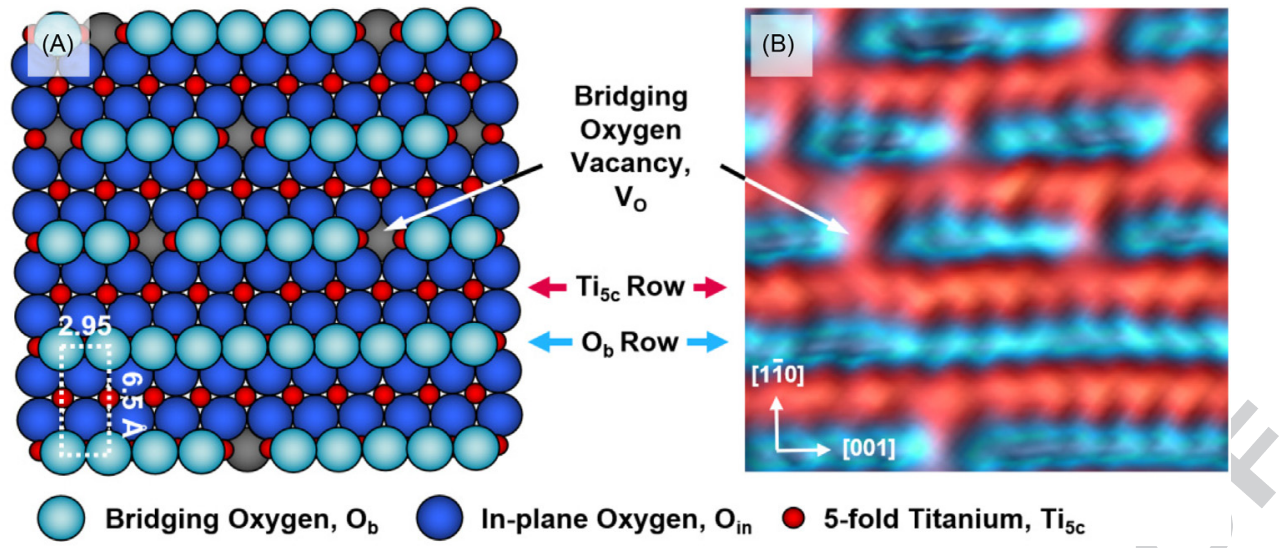

Fig. 3 (A) Structural model of $\mathrm{TiO}_{2}(110)$ surface. (B) Empty-state STM image $\left(V_{\mathrm{G}}=+1 \mathrm{~V}, I_{\mathrm{t}}=0.1 \mathrm{nA}\right)$ depicting the same area, illustrating reversed imaging contrast $\left(\mathrm{Ti}_{5 \mathrm{c}}\right.$ ions appear high and $\mathrm{O}_{\mathrm{b}}$ ions low) dominated by electronic effects. Reproduced with permission from Dohnalek, Z.; Lyubinetsky, I.; Rousseau, R. Thermally-Driven Processes on Rutile $\mathrm{TiO}_{2}(110)-(1 \times 1)$ : A Direct View at the Atomic Scale. Prog. Surf. Sci. 2010, 85 , $161-205$.

p0260 One of the key advantages of STM is its ability to follow extremely low adsorbate coverages. The detection limit is simply defined by the largest area one is willing to analyze, but typically coverages below 0.001 monolayer (ML) can be easily studied ( $1 \mathrm{ML}$ is typically defined as a density of surface atoms and is generally on the order of $10^{15}$ atoms $\left./ \mathrm{cm}^{2}\right)$. In contrast, ensemble average techniques, such as X-ray photoelectron spectroscopy (XPS), infrared reflection absorption spectroscopy (IRRAS), and temperature programmed desorption (TPD), provide at best the detection limit of $\sim 0.01 \mathrm{ML}$.

p0265 Another key strength of STM is the ability to directly identify the preferential adsorption sites. For example, one can easily follow

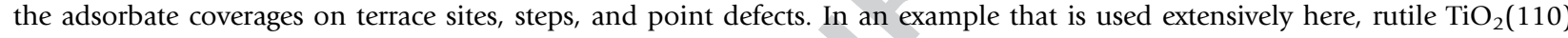
surface (schematically shown in Fig. 3A), the adsorption and reactions on five-fold coordinated surface titanium sites $\left(\mathrm{Ti}_{5 c}\right)$, and missing surface oxygen sites (bridging oxygen vacancies, $\mathrm{V}_{\mathrm{O}}$ 's) are often compared and contrasted. ${ }^{13-15}$ Temperature-dependent measurements can yield further details about the delivery of the adsorbates to specific active sites and their conversion to other surface intermediates.

p0270 While the advantages of the imaging of single molecules on surfaces are indisputable, numerous challenges are present in such experiments. First of all, the studies of adsorbates are generally limited to well-ordered single crystalline surfaces. The complexities of ill-defined substrates such as polycrystalline surfaces and supported nanoclusters quickly impede any possibility of successful interpretation of the data when adsorbates are used. Nanoparticles on its own are very difficult to image at atomic resolution, and only a very few successful examples were reported to date.

p0275 Second, STM lacks the chemical sensitivity. For example, on our prototypical $\mathrm{TiO}_{2}(110)$ surface, the imaging contrast is reversed from the actual surface topography (see Fig. 3) due to electronic effects and the low-lying $\mathrm{Ti}_{5 \mathrm{c}}$ atoms are imaged bright while the ridge $\mathrm{O}_{\mathrm{b}}$ atoms are imaged dark. Similarly, the missing oxygen atoms ( $\mathrm{V}_{\mathrm{O}}$ defects) are imaged bright. Analogous issues persist for adsorbates, and in the Section "Molecular Adsorption" we focus on different approaches that can be employed in determining their chemical identity.

p0280 When STM is used to image the chemical reactions, one of the limiting factors is the slow scanning speed (typically 1 image per minute). The acquisition speed ultimately determines the rate of changes one can follow. As such the ability to adjust the temperature of the sample to limit the rate of diffusion or reaction becomes critical.

p0285 While we have highlighted the ability of STM to follow extremely low coverages, imaging higher coverages becomes increasingly difficult, especially when the molecules do not form ordered structures or the structures are highly fluctuational.

\section{s0040 Reagent Delivery}

p0290 Reagent delivery while avoiding contamination represents one of the critical elements in the studies of adsorbates. Often, other molecules that are present in the chamber background such as $\mathrm{H}_{2} \mathrm{O}, \mathrm{CO}$, and $\mathrm{H}_{2}$ can adsorb and interfere with the experiment. Similarly, care has to be taken to assess possible presence of contaminants in the reagents. Due to the lack of chemical sensitivity of STM, this becomes critical as the identification of the surface species is not straightforward. In many instances, this resulted in serious erroneous assignments and confusion in the literature.

p0295 There are three basic adsorbate delivery methods that are currently being used (Fig. 4). The easiest but also highly questionable method involves simple backfilling of the vacuum chamber with the molecules of interest. This approach inevitably results in complications as the whole systems are being exposed, and molecules can displace other molecules from the chamber walls or even 


\section{IFCC: 12844}
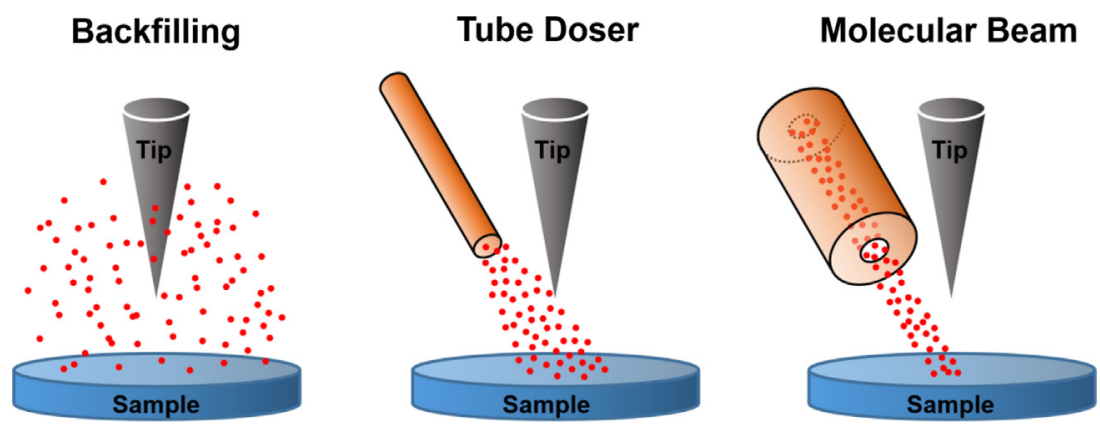

Fig. 4 Three basic adsorbate delivery methods for dosing molecules under UHV conditions.

react forming other products. Additionally, when a low-temperature STM is used, a large buildup of molecular layers on the cooled components can occur.

p0300 Only slightly more complicated method involves the use of tube dosers. ${ }^{16}$ This method lowers the gas load of the system dramatically and delivers the flux of molecules locally on the sample. Components needed include a tube with desired diameter mounted on a retractable stage and a pinhole gasket $(\sim 3 \mu \mathrm{m})$ or a leak valve to control the flux. Many groups attach such dosers directly to the chamber with STM, allowing to image the same area of the sample before and after dosing. During the dose, the STM tip needs to be often retracted several micrometers to avoid tip shadowing of the imaged area. Probing the same area on the sample before and after dosing molecules is experimentally challenging as finding the same nanoscale area can be difficult due to thermal drift. During dosing, the molecules can also adsorb on the apex of the STM tip, making the tunneling conditions unstable.

p0305 The most sophisticated method employs molecular beams. ${ }^{17}$ This allows for ultimate control over the dosed area. Additionally, the translational energy of the molecules can be varied by seeding the molecule of interest in light gasses (i.e., helium and hydrogen) and by heating the orifice that the molecules are emanating from. Such molecular beam sources are complex and consist of several differential pumping stages connected via beam-defining apertures. The purpose of the pumping stages is to eliminate the nondirectional component in the beam. Due to the complexity of such sources, only a limited number of reports exist in the literature. ${ }^{18}$

\section{s0045 Imaging Elemental Steps in Surface Reactions}

p0310 Every encounter, reactive or unreactive, of a molecule with a solid surface can be dissected into a sequence of elementary steps that include adsorption, dissociation, diffusion and rotation, the formation of reaction intermediates, and desorption. Many of such steps can be imaged with a single molecule resolution as a function of time and temperature yielding a wealth of information about the kinetics and dynamics of such processes. Ultimately, when corroborated by theoretical calculations, these measurements can yield unprecedented level of understanding of reaction mechanisms.

\section{s0050 Molecular Adsorption}

p0315 The initial encounter of a molecule with the surface leads to energy transfer, and if sufficient, the molecule thermalizes and adsorbs. For unreactive events, the molecule remains adsorbed on the surface if the substrate temperature is insufficient to provide the energy required for the desorption. Since the energy barriers for the molecules to diffuse on the surface are generally lower than the desorption energy, the adsorbed molecules explore the surface potential energy landscape. The molecules explore various adsorption sites (terrace sites, step sites, point defects), ultimately populating the ones with the highest binding energies. They can also lower their adsorption energy by arranging in preferred configurations relative to other molecules on the surface, e.g., by forming two-dimensional clusters.

p0320 One of the key strengths of STM over ensemble-average techniques such as XPS, TPD of IRRAS is its ability not only to follow the coverage, but also the arrangement, exact adsorption sites at the atomic level, and mutual interactions between adsorbed molecules. A prototypical example is shown for nonreacting CO molecules adsorbed on Pt(111) substrate, which adsorb as isolated molecules at low coverages, form islands of mutually interacting $\mathrm{CO}$ molecules at intermediate coverages, and finally forming ordered highcoverage structures. ${ }^{19}$ All these structures can be easily imaged and unambiguously identified with STM, as shown in Fig. 5.

p0325 Reactive Systems-Understanding What You See

p0330 For the reactive events, additional processes can lead to dissociation, formation of new intermediates, reactions with other adsorbed species, and ultimately to the formation of products. One of many possible sequences of such steps is illustrated in Fig. 6 for the reaction of a simple alcohol molecule (ethanol) on rutile $\mathrm{TiO}_{2}(110),{ }^{14}$ the surface already introduced in Fig. 3. The structure of the catalyst can be altered by interactions with adsorbates as well. In the sections, we present simple examples that illustrate 


\section{IFCC: 12844}

\section{$6 \quad$ Imaging Chemical Reactions One Molecule at a Time}

CO on Pt(111) : As coverage $(\theta)$ increases.
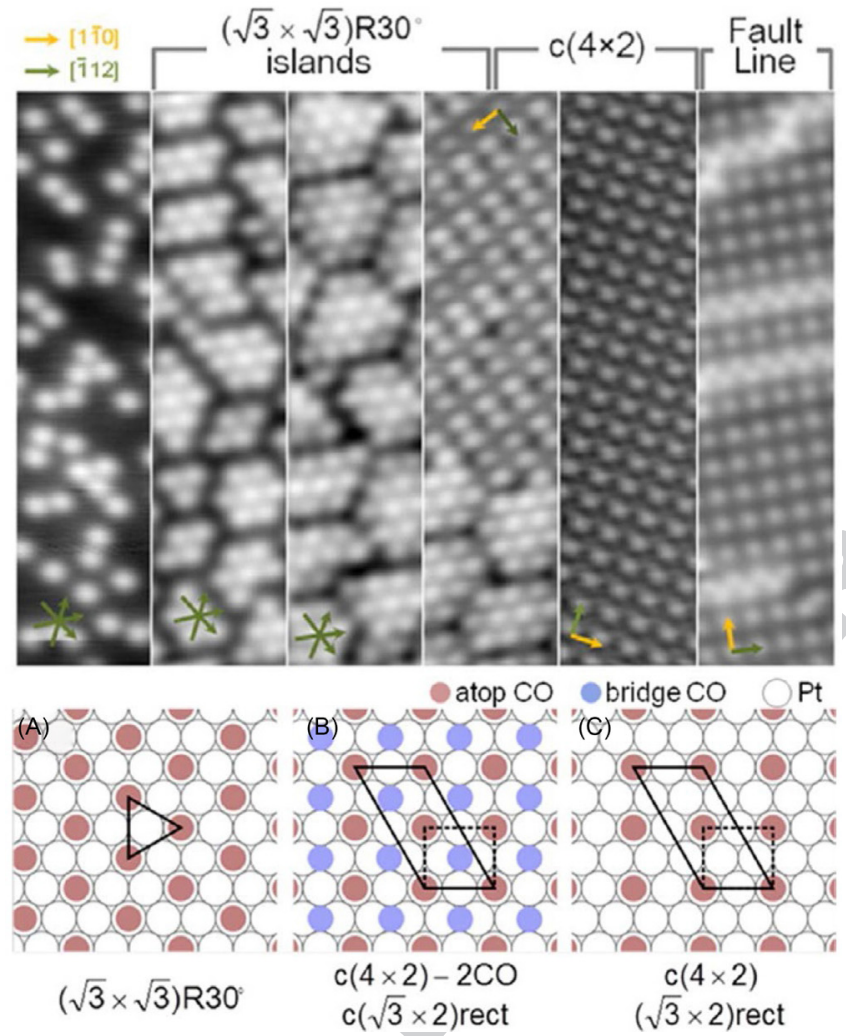

Fig. 5 CO ordering on $\mathrm{Pt}(111)$ as a function of increasing coverage: From isolated molecules to high-coverage superstructures. Adapted with permission from Yang, H. J.; Minato, T.; Kawai, M.; Kim, Y. STM Investigation of CO Ordering on Pt(111): From an Isolated Molecule to High-Coverage Superstructures. J. Phys. Chem. C 2013, 117, 16429-16437.
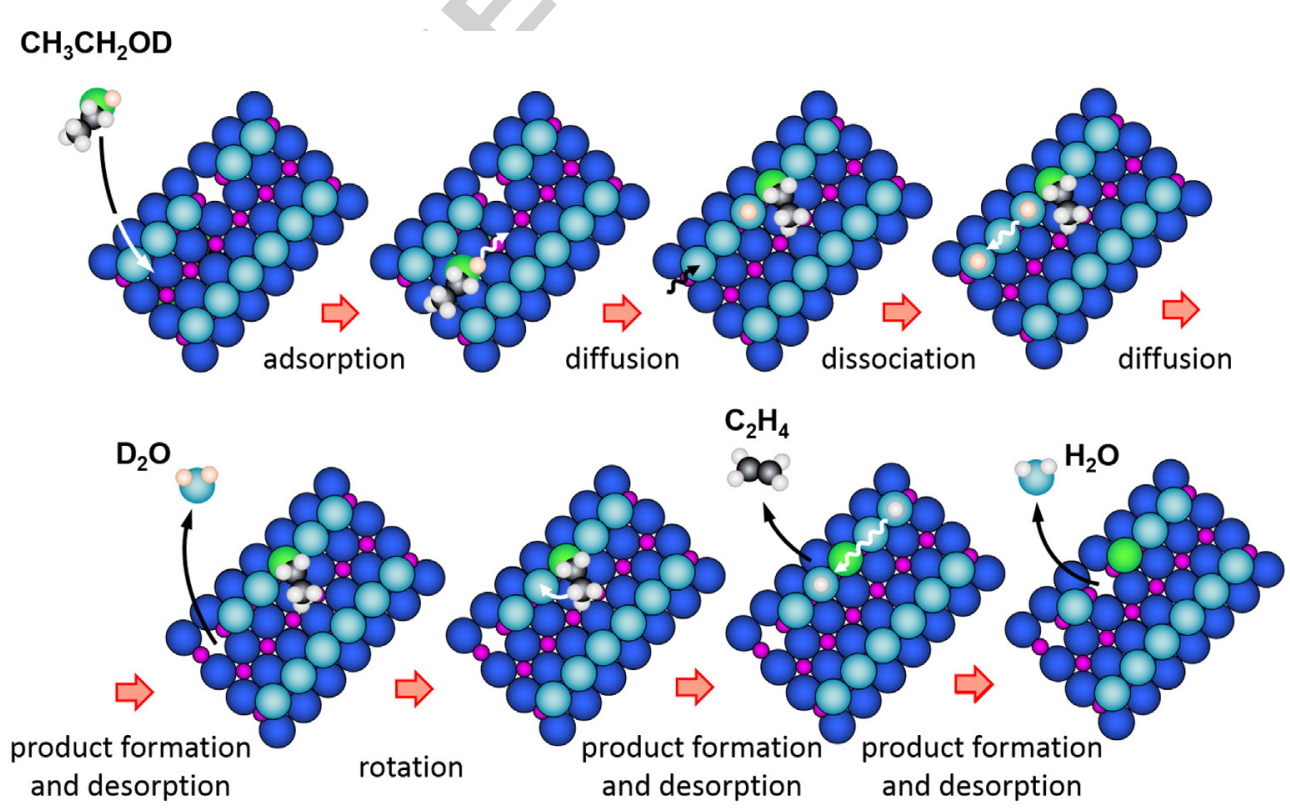

Fig. 6 Schematic representation of elemental steps in alcohol dehydration reaction on $\mathrm{TiO}_{2}(110)$ surface. 


\section{IFCC: 12844}

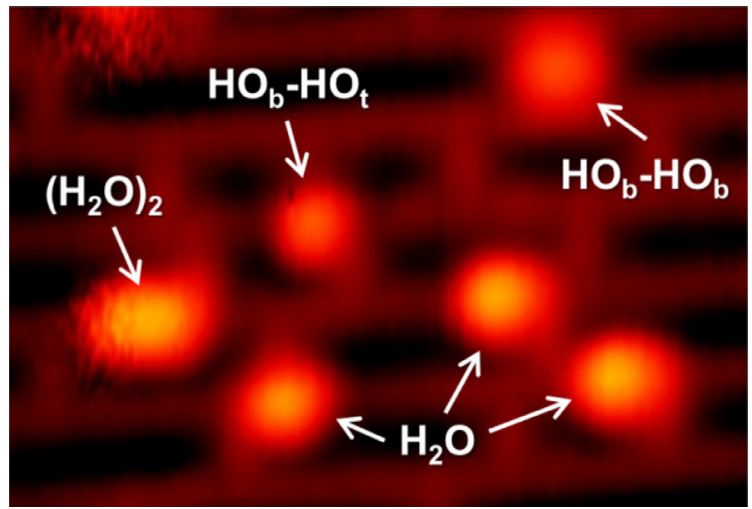

Fig. 7 Adsorption of water on $\mathrm{TiO}_{2}(110)$ at $80 \mathrm{~K}$ yields water monomers and dimers on $\mathrm{Ti}_{5 \mathrm{c}}$ rows, $\mathrm{HO}_{\mathrm{b}}-\mathrm{HO}_{\mathrm{t}}$ pairs on neighboring $\mathrm{O}_{\mathrm{b}}$ and $\mathrm{Ti}_{5 \mathrm{c}}$ sites, and $\mathrm{HO}_{b}-\mathrm{HO}_{\mathrm{b}}$ pairs on $\mathrm{O}_{\mathrm{b}}$ rows. Adapted with permission from Wang, Z.-T.; Wang, Y.-G.; Mu, R.; Yoon, Y.; Dahal, A.; Schenter, G. K.; Glezakou, V.-A.; Rousseau, R.; Lyubinetsky, I.; Dohnálek, Z. Probing Equilibrium of Molecular and Deprotonated Water on $\mathrm{TiO}_{2}(110)$. Proc. Natl. Acad. Sci. U. S. A. 2017, $114,1801-1805$.

studies of such elemental steps, highlight the quantitative information one can extract from a careful analysis, and point out the difficulties and possible pitfalls.

p0335 The first step in understanding the reaction mechanisms is a proper identification of adsorbed species. Even something as simple as a water molecule on $\mathrm{TiO}_{2}(110)$ will look differently depending on the substrate temperature, water coverage, and the site the molecule occupies. This is illustrated in an image presented in Fig. 7. Four types of features can be seen: molecularly bound water monomers, water dimers on bright $\mathrm{Ti}_{5 \mathrm{c}}$ rows, and two different pairs of hydroxyl species, $\mathrm{HO}_{\mathrm{b}}-\mathrm{HO}_{\mathrm{b}}$ and $\mathrm{HO}_{\mathrm{t}}-\mathrm{HO}_{\mathrm{b}}$. The $\mathrm{HO}_{\mathrm{b}}-\mathrm{HO}_{\mathrm{b}}$ pair is a result of water dissociation on the $\mathrm{V}_{\mathrm{O}}$ site:

$$
\mathrm{H}_{2} \mathrm{O}+\mathrm{V}_{\mathrm{O}}+\mathrm{O}_{\mathrm{b}} \rightarrow 2 \mathrm{HO}_{\mathrm{b}}
$$

and the $\mathrm{HO}_{\mathrm{t}}-\mathrm{HO}_{\mathrm{b}}$ pair is formed by dissociation of $\mathrm{Ti}_{5 \mathrm{c}}$-bound water monomer:

$$
\mathrm{H}_{2} \mathrm{O}+\mathrm{O}_{\mathrm{b}} \rightarrow \mathrm{HO}_{\mathrm{t}}+\mathrm{HO}_{\mathrm{b}}
$$

p0345 Why do the species shown in Fig. 7 coexist on the surface? The expectation is that the most stable configuration would dominate as indicated earlier. The key is that this experiment has been performed at $80 \mathrm{~K}$, well below the onset of diffusion $(\sim 170 \mathrm{~K})$, and hence all the species are formed by a direct adsorption on the specific site. The image, therefore, illustrates a nonequilibrated scenario with kinetically frozen intermediate states.

p0350 How does one go about determining the chemical identity of the observed species? The helpful starting point is understanding as much as possible about the chemistry using the ensemble averaged techniques. For example, TPD can provide information about at what temperature the reactants and products desorb, and IRRAS and XPS can provide chemical fingerprints of certain surface intermediates. While not necessary, such information can help to avoid mistakes in the subsequent STM assignments. Below we illustrate the procedures one can apply in pursuing the assignment of the surface species with STM.

\section{s0055 Same area imaging}

p0355 Comparing the same area before and after adsorption is critical as the initial image provides the map of initial surface sites including defects, steps, and molecules already adsorbed on the surface. Fig. 8 illustrates this approach in imaging $\mathrm{H}_{2} \mathrm{O}$ dissociation on $\mathrm{V}_{\mathrm{O}}$ sites on $\mathrm{TiO}_{2}(110){ }^{20}$ The identification of the initial $\mathrm{V}_{\mathrm{O}}$ concentration and their positions are the key (Fig. 8, left). After $\mathrm{H}_{2} \mathrm{O}$ adsorption, the same area image shows one bright species centered on the original $\mathrm{V}_{\mathrm{O}}$ (Fig. 8, middle) and one on neighboring $\mathrm{O}_{b}$ site. The observation of two features and their relative positions with respect to the original $V_{O}$ is a key piece of evidence leading to the conclusion that water dissociated in the $\mathrm{V}_{\mathrm{O}}$ (see the reaction scheme above) and formed a pair of bridging hydroxyl species $\left(\mathrm{HO}_{\mathrm{b}}\right)$. Further time-dependent evolution of the area illustrates the diffusion of one of the $\mathrm{HO}_{\mathrm{b}}$ 's (Fig. 8, right) confirming the assignment. Line profiles along the low-index crystallographic directions over the observed features facilitate the analysis further. While this process seems simple, it is not often adopted as imaging the same area during the adsorption is difficult.

\section{s0060 Bias- and tunneling current-dependent imaging}

p0360 Another key identification method utilizes the bias and tunneling current dependence to identify/distinguish the surface species. For example, the $\mathrm{HO}_{\mathrm{b}}$ appearance on $\mathrm{TiO}_{2}(110)$ can change dramatically relative to the underlying lattice and $\mathrm{V}_{\mathrm{O}}$ defects. ${ }^{21}$ As shown in Fig. 9, for one particular bias, a simple variation of the tunneling current can make them stand out very clearly (Fig. 9A), make them appear practically identical with $V_{O}$ 's (Fig. 9C), or make them invisible (Fig. 9D). When the initial surface becomes completely hydroxylated prior to the initial imaging one could easily arrive to the conclusion that the surface is clean and contains only $\mathrm{V}_{\mathrm{O}}$ 's. 


\section{IFCC: 12844}
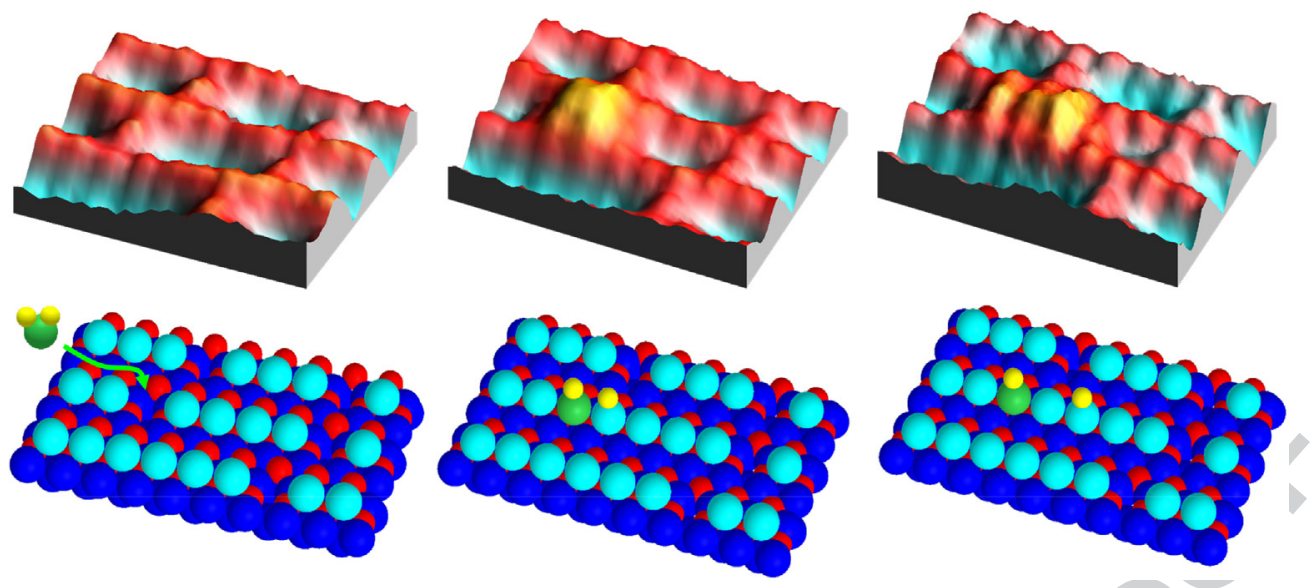

Fig. 8 STM images (top pane/s) and corresponding ball models (bottom panels) of $\mathrm{H}_{2} \mathrm{O}$ adsorption, dissociation to bridging hydroxyls (Reaction 1), and hydroxyl hydrogen diffusion on $\mathrm{TiO}_{2}(110)$. Light blue ball: oxygen atom, red ball: Ti atom. Reproduced with permission from Dohnalek, Z;; Lyubinetsky, I.; Rousseau, R., Thermally-driven processes on rutile $\mathrm{TiO}_{2}(110)-(1 \times 1)$ : A direct View at the Atomic Scale. Prog. Surf. Sci. 2010, 85 , $161-205$.

s0065 Scanning tunneling spectroscopy ${ }^{22}$

p0365 In addition to the imaging, scanning tunneling spectroscopy (STS) provides site-resolved information about the available empty and filled density of states (DOS) as a function of energy. The STS spectra are obtained by placing the STM tip above a particular site on the sample. With the height of the tip fixed, the electron tunneling current is measured as a function of electron energy by varying the voltage between the tip and the sample. STS obtained at different sites allows for the correlation of the DOS with specific atomic sites or adsorbed species. While the measurements are relatively simple, a stable and well-defined metallic tip apex is a prerequisite for reliable STS measurements. Such conditions are generally hard to achieve on complex materials such as oxides, in particular, if the tip is held at room temperature.

p0370 Fig. 10 shows a nice illustration of the STS spectra for the $\mathrm{TiO}_{2}(110)$ prototype (see Fig. 3) that were used to identify the spatial distribution of the excess charge created by $\mathrm{V}_{\mathrm{O}}$ defects. ${ }^{23}$ The spectra taken at the $\mathrm{V}_{\mathrm{O}}$ and nearby $\mathrm{Ti}_{5 \mathrm{c}}$ sites show that the excess electron density spreads from the $\mathrm{V}_{\mathrm{O}}$ onto the neighboring $\mathrm{Ti}_{5 \mathrm{c}}$ sites retaining very negligible density on the proximate $\mathrm{Ti}_{6 \mathrm{c}}$ ions. STS confirms the presence of occupied $\mathrm{Ti}^{3+}$ defect states as observed in ultraviolet photoemission spectroscopy (UPS).

\section{s0070 Tip-induced manipulations}

p0375 Ultimately, harsh imaging conditions (high bias and/or current) can be used to alter the adsorbed species. ${ }^{24}$ When done in a controlled way, such tip-induced manipulations can serve as a diagnostic method to distinguish or identify certain types of species. For example, the tip-induced removal of the $\mathrm{HO}_{\mathrm{b}}$ hydrogen, illustrated in Fig. 11, settled the long dispute in the identification of $\mathrm{HO}_{\mathrm{b}}$ 's and $\mathrm{V}_{\mathrm{O}}$ 's. ${ }^{25} \mathrm{~A}$ word of caution: while the tip-induced processes can be used as a diagnostic or even to induce surface reactions and changes in the adsorbate conformation, they can also result in unintended consequences. For example, for sensitive adsorbates, such as $\mathrm{O}_{2}$ on $\mathrm{TiO}_{2}(110)$, the dissociation can occur efficiently even under the mildest imaging conditions and lead to erroneous conclusion about the dissociation of $\mathrm{O}_{2}$ at low temperatures $(<150 \mathrm{~K}) \cdot{ }^{26}$ Interpreting the STM images while taking into account the results of prior ensemble averaged studies cannot be stressed enough.

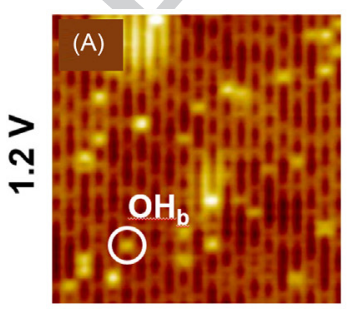

$50 \mathrm{pA}$

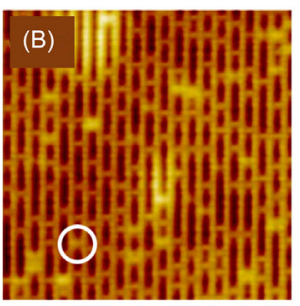

$100 \mathrm{pA}$

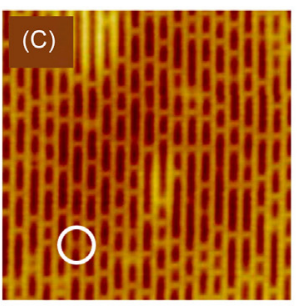

$300 \mathrm{pA}$

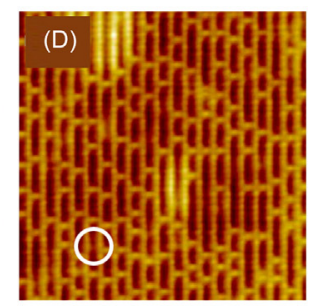

700 pA

Fig. 9 Room temperature STM images of the same area $\left(14 \times 14 \mathrm{~nm}^{2}\right)$ of the partially hydroxylated $\mathrm{TiO}_{2}(110)$ surface under different imaging conditions. The sequence illustrates how the appearance of the $\mathrm{HO}_{\mathrm{b}}$ species changes relative to the $\mathrm{V}_{0} \mathrm{~S}$ as the tunneling current is increased. Adapted with permission from Cui, X. F.; Wang, Z.; Tan, S. J.; Wang, B.; Yang, J. L.; Hou, J. G. Identifying Hydroxyls on the $\mathrm{TiO}_{2}(110)-1 \times 1$ Surface with Scanning Tunneling Microscopy. J. Phys. Chem. C 2009, 113, 13204-13208. 


\section{IFCC: 12844}

Fig. 10 STS I/V (inset) and $d / / d V$ spectra of the site-dependent occupied DOS in the vicinity of a $V_{0}$ site on $\mathrm{TiO}_{2}(110)$ surface measured at $78 \mathrm{~K}$. Spectra are acquired (A) at the center of a lobe in the occupied STM image between the second and third $\mathrm{Ti}_{5 c}$ sites away from the $\mathrm{V}_{0}$, (B) at a $\mathrm{Ti}_{6 \mathrm{c}}$ site, and $(C)$ at the $V_{0}$ site. Measurements demonstrate that the charge state at $-0.8 \mathrm{eV}$ is located on the $\mathrm{Ti}_{5 \mathrm{c}}$ sites that are between one and four sites away from the $V_{0}$. Reproduced from Minato, T.; Sainoo, Y.; Kim, Y.; Kato, H. S.; Aika, K.; Kawai, M.; Zhao, J.; Petek, H.; Huang, T.; He, W.; Wang, B.; Wang, Z.; Zhao, Y.; Yang, J. L.; Hou, J. G. The Electronic Structure of Oxygen Atom Vacancy and Hydroxyl Impurity Defects on Titanium Dioxide (110) Surface. J. Chem. Phys. 2009, 130, 124502 with the permission of AIP Publishing.

(A)

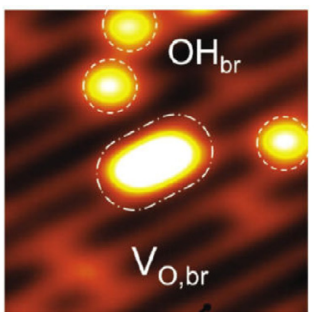

$\mathrm{Ti}_{5 f}$

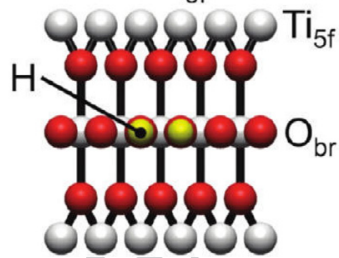

(B)
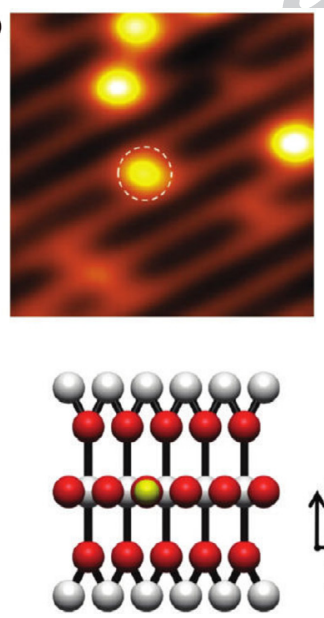

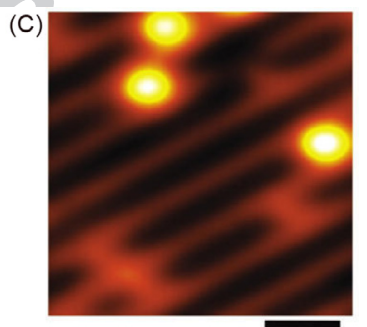

$\overline{1 \mathrm{~nm}}$

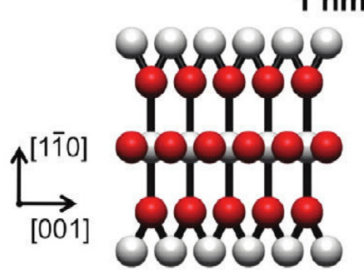

Fig. 11 Controlled desorption of individual $\mathrm{H}$ atoms from $\mathrm{HO}_{\mathrm{b}}$ pair (labeled as $\mathrm{OH}_{\mathrm{br}}$ in the figure) on $\mathrm{TiO}_{2}(110)$. Reproduced with permission from

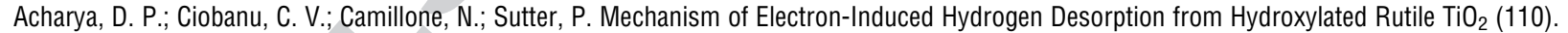
J. Phys. Chem. C 2010, 114, 21510-21515.

\section{s0075 Simulation of STM images}

p0380 To further understand the adsorption configuration of the surface species, theoretical calculations of the optimized geometry, electronic structure, and the charge density distribution are often carried out. The results of such calculations can be utilized to simulate the STM images ${ }^{27}$ that can be compared with the experimentally measured images.

p0385 For example, for $\mathrm{H}_{2} \mathrm{O}$ adsorbed on anatase $\mathrm{TiO}_{2}(101)$, the arch-like features are observed (Fig. 12A) ${ }^{28}$ It is not clear from the STM image whether these features are isolated water molecules, water clusters, or dissociated water. Density functional theory (DFT) simulations yielded the adsorption structure (Fig. 12B), charge distribution of water monomer (Fig. 12C), and the STM images (Fig. 12D). The agreement between the simulations and the experimental images strongly supports the fact that water is bound molecularly on this particular surface. 


\section{IFCC: 12844}
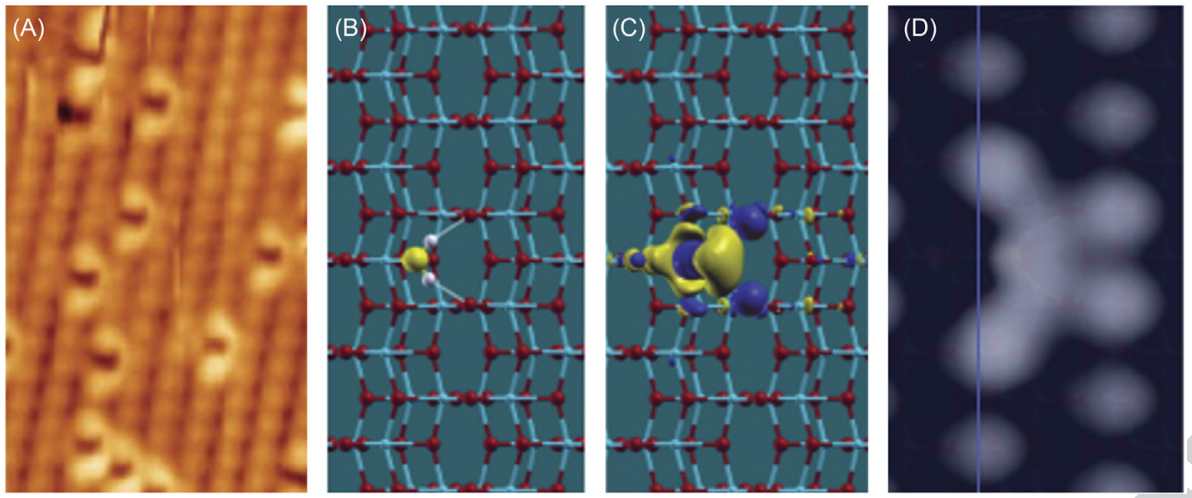

Fig. 12 a) STM images of isolated water molecules on anatase $\mathrm{TiO}_{2}(101)$ taken at a sample temperature of $190 \mathrm{~K}(+3.5 \mathrm{~V}, 0.45 \mathrm{nA})$. (B-D) Theoretical results for an adsorbed water monomer on anatase $\mathrm{TiO}_{2}(101)$. (B) Optimized geometry (top view) (C) isosurface of the charge density difference resulting from the adsorption of a water molecule. Positive (electron excess) and negative (electron deficit) lobes are shown in blue and yellow, respectively. (D) Simulated constant density image, determined from the integrated local density of states in an energy window of $2.75 \mathrm{eV}$ from the conduction band minimum. Adapted with permission from He, Y.; Tilocca, A.; Dulub, 0.; Selloni, A.; Diebold, U. Local Ordering and Electronic Signatures of Submonolayer Water on Anatase $\mathrm{TiO}_{2}(101)$. Nat Mater 2009, 8, 585-589.
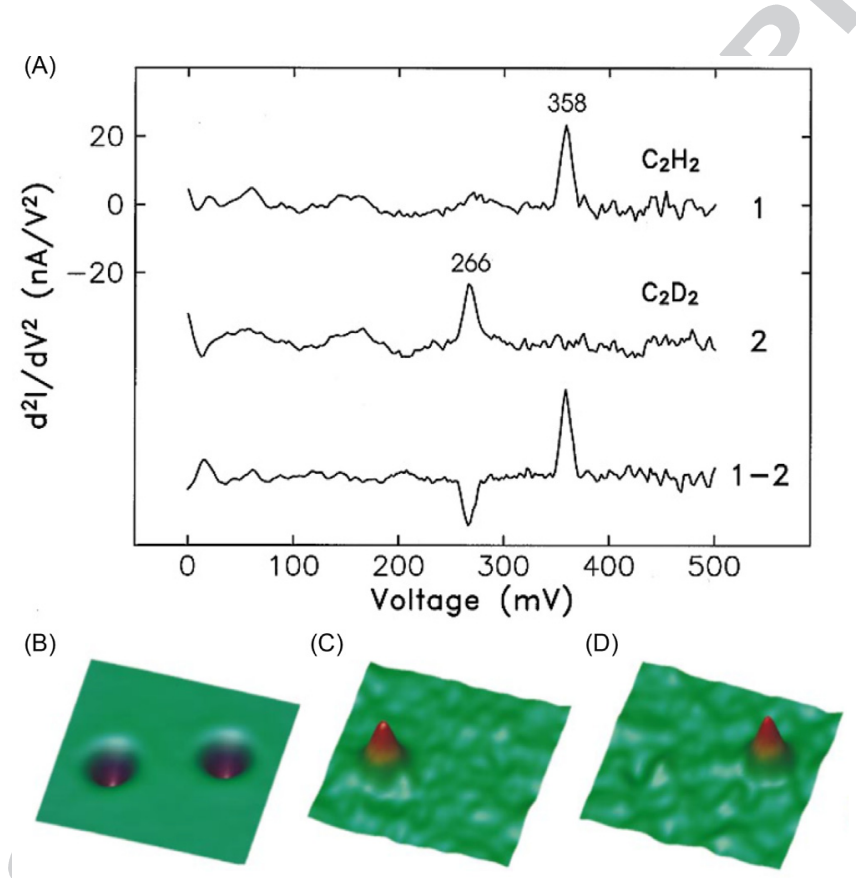

Fig. 13 (A) IETS $\mathrm{d}^{2} / / \mathrm{dV}^{2}$ spectra for $\mathrm{C}_{2} \mathrm{H}_{2}(1)$ and $\mathrm{C}_{2} \mathrm{D}_{2}$ (2) on $\mathrm{Cu}(100)$ show $\mathrm{C}-\mathrm{H}(1)$ and $\mathrm{C}-\mathrm{D}$ (2) vibrational peaks at $358 \mathrm{mV}$ and $266 \mathrm{mV}$, respectively. (1-2) shows the difference spectrum. (B) Regular (constant current) STM image $\left(4.8 \times 4.8 \mathrm{~nm}^{2}\right)$ of a $\mathrm{C}_{2} \mathrm{H}_{2}$ (left) and a $\mathrm{C}_{2} \mathrm{D}_{2}$ molecule (right). Spectroscopic $\mathrm{d}^{2} \mathrm{I} / \mathrm{dV}^{2}$ spatial imaging of the inelastic channels for $(\mathrm{C}) \mathrm{C}_{2} \mathrm{H}_{2}$ and $(\mathrm{D}) \mathrm{C}_{2} \mathrm{D}_{2}$ recorded at 358 and $266 \mathrm{mV}$, respectively. Adapted with permission from Stipe, B. C.; Rezaei, M. A.; Ho, W., Single-Molecule Vibrational Spectroscopy and Microscopy. Science 1998, 280, $1732-1735$.

\section{s0080 Inelastic electron tunneling spectroscopy}

p0390 One of the advanced approaches to chemical fingerprinting of the adsorbed species involves inelastic electron tunneling spectroscopy (IETS). In the experiment, the tunneling current, $I_{\mathrm{G}}$ is measured as a function of voltage, $V_{\mathrm{G}}$ across the junction. Small, sharp steps in the conductance, $\mathrm{d} I / \mathrm{d} V$, can be observed when the energy of the tunneling electrons reaches the energy of a vibrational mode for molecules in the junction and the $\mathrm{d}^{2} \mathrm{I} / \mathrm{dV}^{2}$ spectra are normally plotted to clearly see the changes in the conductance. This increase is the result of electrons losing their energies to the vibrational mode, giving rise to an inelastic tunneling channel, which is forbidden when tunneling electrons have energies below the quantized vibrational energy. The IETS measurements are experimentally extremely involved, require extremely high signal-to-noise ratio, and have to be carried out at liquid He temperatures.

p0395 An example from the pioneering work of Ho's group is shown in Fig. $13 .{ }^{29}$ Here, the inelastic electron tunneling spectra for an isolated acetylene $\left(\mathrm{C}_{2} \mathrm{H}_{2}\right)$ molecule on $\mathrm{Cu}(100)$ showed an increase in the tunneling conductance at a vibrational voltage of 


\section{IFCC: 12844}

$358 \mathrm{mV}$, resulting from excitation of the $\mathrm{C}-\mathrm{H}$ stretch mode. An isotopic shift to $266 \mathrm{mV}$ was observed for deuterated acetylene $\left(\mathrm{C}_{2} \mathrm{D}_{2}\right)$. While a $\mathrm{C}_{2} \mathrm{H}_{2}$ and a $\mathrm{C}_{2} \mathrm{D}_{2}$ appear the same in the regular STM image (Fig. 13B), only one molecule $\left(\mathrm{C}_{2} \mathrm{H}_{2}\right.$ or $\left.\mathrm{C}_{2} \mathrm{D}_{2}\right)$ was revealed in the vibrational imaging conducted at the correlated vibrational voltage (358 and $266 \mathrm{mV}$ in Fig. 13A spectrum 1 and 2 , respectively). For semiconductor surfaces, recording the IETS spectra is challenging due to the absence of states around the Fermi level. Recently, Kern's group demonstrates IETS on a highly $n$-doped anatase $\mathrm{TiO}_{2}(101)$ surface to chemically identify single water molecules and hydroxyl species. ${ }^{30}$

p0400 Ho's group further pushed the spatial resolution of the STM to molecular structure and chemical bonding by employing IETS with functionalized STM tips. ${ }^{31}$ They used CO-terminated tip to probe the local potential energy landscape of an adsorbed molecule. As the CO-terminated tip is scanned over the molecule during imaging, changes in the energy and intensity of the hindered translational vibration of $\mathrm{CO}$ on the tip are measured by IETS, revealing the skeletal structure and bonding of the molecule as shown in Fig. 14. An application of the inelastic tunneling to probe cobalt phthalocyanine in Fig. 14 reveals the sharing of hydrogen atoms among multiple centers in intramolecular and extramolecular hydrogen bonds.

\section{s0085 Adsorbate Motion}

p0405 The delivery of reactants and intermediates to the reaction sites is often mediated by their diffusion on the catalyst surface from their adsorption or generation site. As such, this step represents an important part of the reaction mechanisms. Below we will illustrate two basic types of motions, rotational diffusion, which can lead to the proper alignment of the adsorbed species with the active site to facilitate the reaction, and translational diffusion, which facilitates delivery to the active site.

\section{so090 Rotational dynamics}

p0410 The STM images of adsorbed species are hardly ever a static representation of their structure. Depending on the temperature, the molecules can access a range of rotational and vibrational configurations which can significantly affect their appearance during long STM imaging timescales. As a result, the image often represents a time average of probability-weighted configurations accessed by the adsorbate during the image acquisition. For example, the images of acetylene shown in Fig. 13B-D appear circular despite the elliptical profile of the molecule. As suggested by the authors, ${ }^{29}$ the appearance is likely a result of the fast rotational motion between two equivalent configurations on the surface. At the experimental temperature of $8 \mathrm{~K}$, this represents a rotational barrier that has to be very small $(<2 \mathrm{~kJ} / \mathrm{mol})$.

p0415 The rotational dynamics has been clearly visualized for 1-, 2-,3-, and 4-octoxy species anchored on the $\mathrm{O}_{\mathrm{b}}$ rows of rutile $\mathrm{TiO}_{2}(110)$ as shown in Fig. $15{ }^{32}$ The octoxy species have been prepared by dissociating the octanol molecules (ROH) via $\mathrm{O}-\mathrm{H}$ bond cleavage on the $\mathrm{V}_{\mathrm{O}}$ sites (see Fig. 6); the step analogous with the dissociation of water discussed earlier (Reaction 1 and Fig. 8):

$$
\mathrm{R}-\mathrm{OH}+\mathrm{V}_{\mathrm{O}}+\mathrm{O}_{\mathrm{b}} \rightarrow \mathrm{RO}_{\mathrm{b}}+\mathrm{HO}_{\mathrm{b}}
$$

p0420 Instead of a single bright elongated lobe as expected for the alkyl chain of a static 1-, 2-, and 3-octoxy species, bright " $\mathrm{X}$ "-shaped features centered above the original position of the $\mathrm{V}_{\mathrm{O}}$ with four lobes stretching onto the neighboring $\mathrm{Ti}_{5 \mathrm{c}}$ rows are observed for 1-, $2-$, and 3-octoxy species. These " $\mathrm{X}$ "-shaped features are a consequence of the alkyl chain rotation between four equivalent local energy minima around the anchoring $\mathrm{C}-\mathrm{O}_{\mathrm{b}}$ bond with a rate that is fast compared to the slow STM acquisition rate. The acquired images, therefore, represent a time average of the alkoxy species in these four positions as schematically illustrated in the ball model insets. This trend is completed for 4-octanol, Fig. 15D, where instead of an " $\mathrm{X}$ "- and "I"-shaped feature perpendicular to the $\mathrm{O}_{\mathrm{b}}$ row is observed. In all cases, the alkyl chains are located on $\mathrm{Ti}_{5 \mathrm{c}}$ rows and minimize their overlap with the $\mathrm{O}_{\mathrm{b}}$ rows. This is simply due to increased van der Waals interaction of the hydrocarbon chains with $\mathrm{Ti}^{4+}$ cations over $\mathrm{O}^{2-}$ anions.
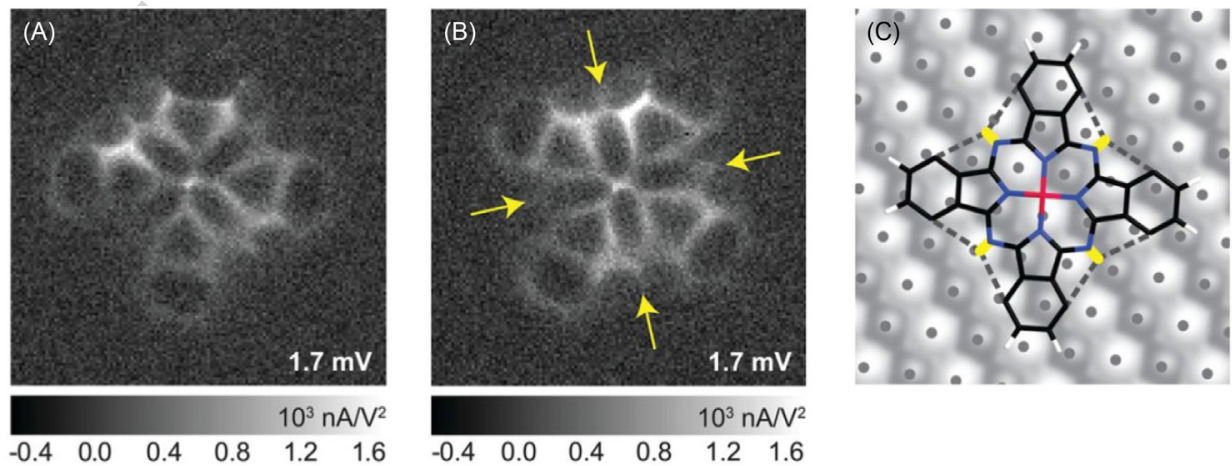

Fig. 14 Skeletal images of cobalt phthalocyanine ( $\mathrm{CoPc}$ ) with two different configurations, labeled $\mathrm{CoPc}(x)$ and $\mathrm{CoPc}(+)$, obtained by inelastic tunneling probe (itProbe). Constant-height images over (A) $\mathrm{CoPc}(+)$ and $(\mathrm{B}) \mathrm{CoPc}(\times)$ on $\mathrm{Ag}(110)$. (C) Schematic diagram showing the skeletal structure of $\mathrm{CoPc}(+)$ and the intramolecular hydrogen bonds (dashed lines). Adapted with permission from Chiang, C.-I.; Xu, C.; Han, Z.; Ho, W. Real-Space Imaging of Molecular Structure and Chemical Bonding by Single-Molecule Inelastic Tunneling Probe. Science 2014, 344, 885-888. 


\section{IFCC: 12844}
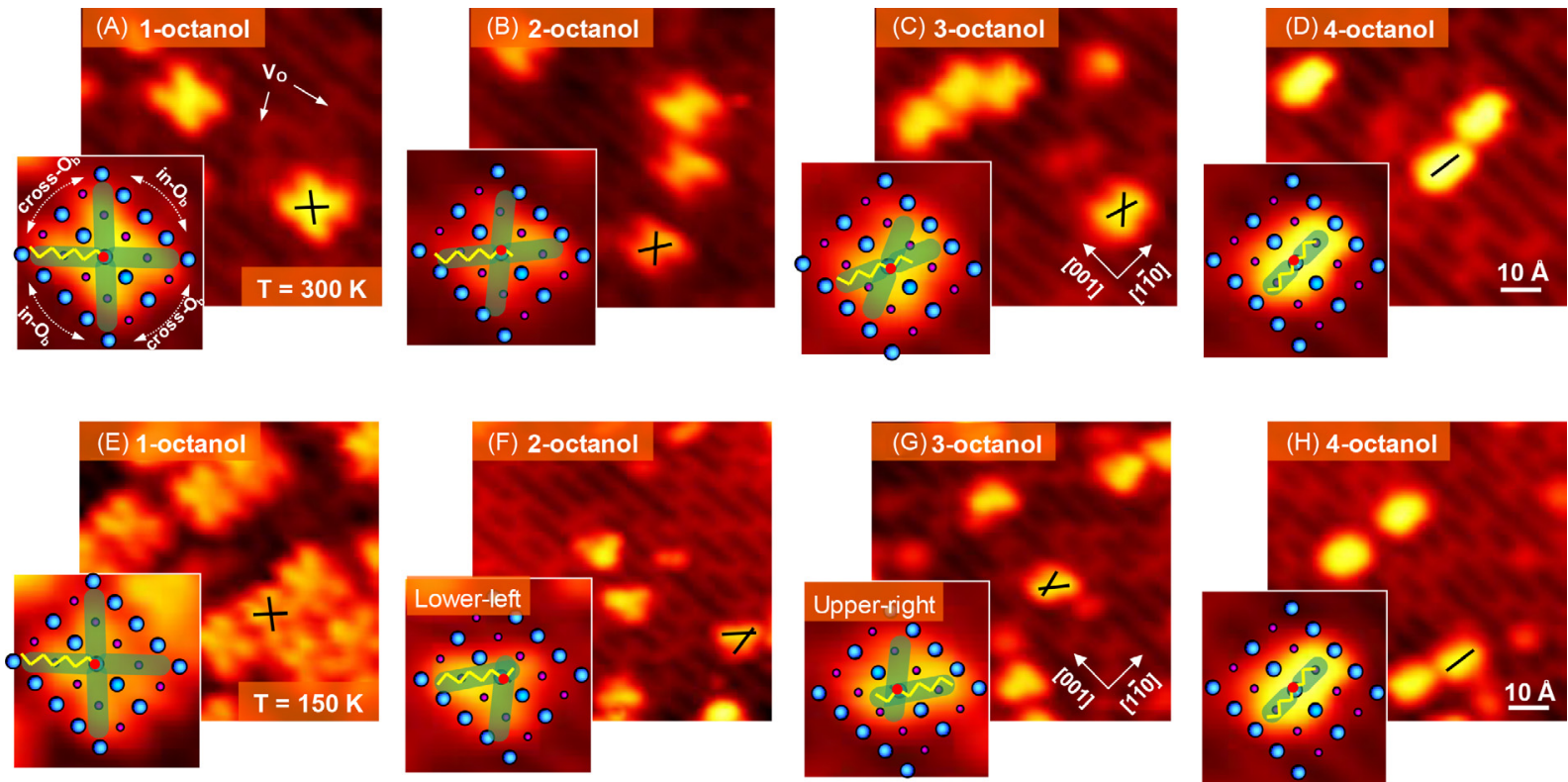

Fig. 15 The STM images of $\mathrm{TiO}_{2}(110)$ after adsorption of (A),(E) 1-, (B),(F) 2-, (C), (G) 3-, and (D), (H) 4-octanol at $300 \mathrm{~K}$. Imaging was conducted at $300 \mathrm{~K}(\mathrm{~A})-(\mathrm{D})$ and $150 \mathrm{~K}(\mathrm{~F})-(\mathrm{H})$. The insets show magnified areas with the octoxy species overlaid by $\mathrm{TiO}_{2}(110)$ ball models $\left(\mathrm{O}_{\mathrm{b}}\right.$ : blue, $\mathrm{Ti}_{5 \mathrm{c}}$ : magenta) The yellow zigzag lines illustrate the octyl chains; red dots mark the anchoring position on the $\mathrm{O}_{b}$ row. Green lobes forming an "X" shape for 1-, 2-, and 3-octoxy and "I" shape for 4-octoxy indicate how fast rotation of the octoxy species lead to the formation of such features in the STM images. Adapted with permission from Zhang, Z.; Rousseau, R.; Gong, J.; Kay, B. D.; Dohnalek, Z. Imaging Hindered Rotations of Alkoxy Species on $\mathrm{TiO}_{2}(110)$. J. Am. Chem. Soc. 2009, 131, 17926-17932.
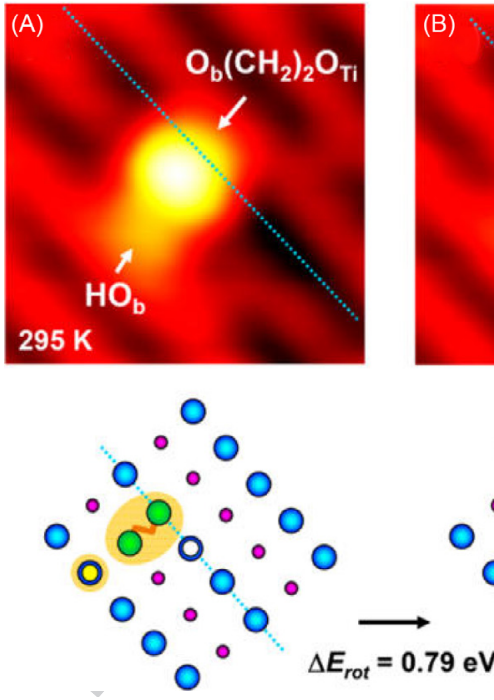
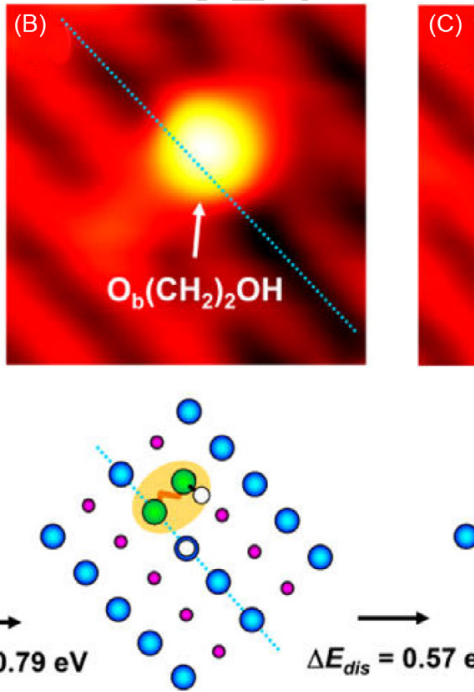
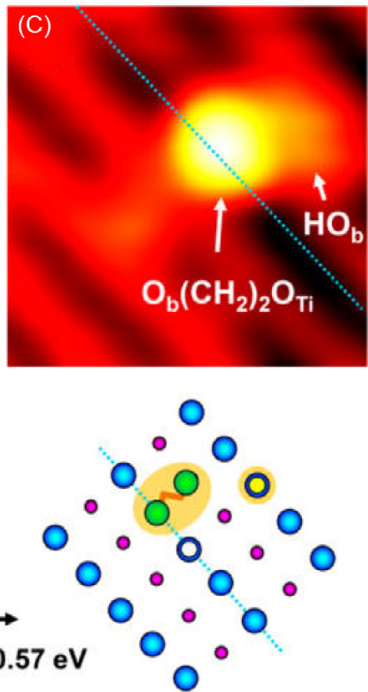

Fig. 16 Time-lapse sequence of STM images of the same area on $\mathrm{TiO}_{2}(110)$ obtained after the exposure to ethane-1,2-diol at $295 \mathrm{~K}$. The schematics below the images indicate the observed processes. (A) $\rightarrow$ (B) Formation of the hydroxyethoxy species, $\mathrm{O}_{\mathrm{b}}-\left(\mathrm{CH}_{2}\right)_{2}-\mathrm{OH}$, from the bridging hydroxyl, $\mathrm{HO}_{\mathrm{b}}$, and the diethoxy, $\mathrm{O}_{\mathrm{b}}-\left(\mathrm{CH}_{2}\right)_{2}-\mathrm{O}_{\mathrm{Ti}}$, species (not observed directly). Following its formation, the $\mathrm{O}_{\mathrm{b}}-\left(\mathrm{CH}_{2}\right)_{2}-\mathrm{OH}$ rotates around its anchoring $\mathrm{O}_{\mathrm{b}}$ site. $(B) \rightarrow(C)$ Deprotonation of the $\mathrm{O}_{b}-\left(\mathrm{CH}_{2}\right)_{2}-\mathrm{OH}$ to $\mathrm{O}_{\mathrm{b}}-\left(\mathrm{CH}_{2}\right)_{2}-\mathrm{O}_{\mathrm{Ti}}$ and $\mathrm{HO}_{\mathrm{b}}$. The energy barriers for the $\mathrm{O}_{\mathrm{b}}-\left(\mathrm{CH}_{2}\right)_{2}-\mathrm{OH}$ dissociation $\left(\Delta \mathrm{E}_{\text {dis }}\right)$ and rotation $\left(\Delta \mathrm{E}_{\mathrm{rot}}\right)$ were determined via DFT. Reproduced with permission from Acharya, D. P.; Yoon, Y.; Li, Z.; Zhang, Z.; Lin, X.; Mu, R.; Chen, L.; Kay, B. D.; Rousseau, R.; Dohnalek, Z. Site-Specific Imaging of Elemental Steps in Dehydration of Diols on $\mathrm{TiO}_{2}(110)$. ACS Nano 2013, 7, 10414-10423.

Direct evidence for the rotation of the octoxy species was further obtained by imaging the octoxy species at $150 \mathrm{~K}$ as shown in Fig. 15E-H. While the appearance of 1-octoxy species (Fig. 15E) remains " $\mathrm{X}$ " shaped, 2- and 3-octoxy (Fig. 15F and G) became "V" shaped due to frozen cross- $\mathrm{O}_{\mathrm{b}}$ row rotational motion. 
p0430 A more complex example demonstrating a combination of rotational motion with a reversible reaction is shown in Fig. 16 . $^{33}$ Here a hydroxyethoxy species, $\mathrm{O}_{\mathrm{b}}-\left(\mathrm{CH}_{2}\right)_{2}-\mathrm{OH}$, is formed by 1,2-ethanediol (ethylene glycol) dissociation on the $\mathrm{V}_{\mathrm{O}}$ sites of $\mathrm{TiO}_{2}(110)$ :

$$
\mathrm{HO}-\left(\mathrm{CH}_{2}\right)_{2}-\mathrm{OH}+\mathrm{V}_{\mathrm{O}}+\mathrm{O}_{\mathrm{b}} \rightarrow \mathrm{O}_{\mathrm{b}}-\left(\mathrm{CH}_{2}\right)_{2}-\mathrm{OH}+\mathrm{HO}_{\mathrm{b}}
$$

p0435 This species is anchored by one oxygen on the $\mathrm{O}_{\mathrm{b}}$ row, while its second, hydroxyl oxygen is bound to the neighboring $\mathrm{Ti}_{5 \mathrm{c}}$ site. The species rotates slowly at $300 \mathrm{~K}$ between the two equivalent $\mathrm{Ti}_{5 \mathrm{c}}$ rows that are neighboring the anchoring $\mathrm{O}_{\mathrm{b}}$ site. At the same time, a reversible reaction leads to deprotonation of the $\mathrm{Ti}_{5 \mathrm{c}}$ bound hydroxyl:

$$
\mathrm{O}_{\mathrm{b}}-\left(\mathrm{CH}_{2}\right)_{2}-\mathrm{OH}+\mathrm{O}_{\mathrm{b}} \rightleftarrows \mathrm{O}_{\mathrm{b}}-\left(\mathrm{CH}_{2}\right)_{2}-\mathrm{O}_{\mathrm{Ti}}+\mathrm{HO}_{\mathrm{b}}
$$

Following the deprotonation, a stronger bond between the dioxo $\mathrm{O}_{\mathrm{Ti}}$ oxygen and the $\mathrm{Ti}_{5 \mathrm{c}}$ site prevents further rotation until the hydroxyethoxy species is reformed.

s0095 Surface diffusion

p0445 Surface diffusion represents a critical step in most catalytic reactions. Under reaction conditions, it efficiently supplies reagents to active sites and mediates steps that involve more than one surface species. The mobility of one species can also mediate mobility of other species. We provide several examples that illustrate such processes and quantitative information that can be obtained from imaging.

p0450 We start with a simple example of $\mathrm{HO}_{\mathrm{b}}$ hydrogen diffusion on $\mathrm{O}_{\mathrm{b}}$ rows of $\mathrm{TiO}_{2}(110)$ that was illustrated in Fig. $8 .{ }^{20}$ While the images provide a clear indication of the along-the-row directionality of the motion and the onset temperature of $\sim 300 \mathrm{~K}$, more detailed temperature-dependent studies coupled with theoretical simulations yield information about the mechanism and kinetic parameters. ${ }^{34}$ The temperature-dependent hydrogen and deuterium isotope experiments further yield the diffusion activation energies of $0.74 \mathrm{eV}$ and $0.85 \mathrm{eV}$ and prefactors of $10^{7.3}$ and $10^{8.6} \mathrm{~s}^{-1}$, respectively. The differences in the parameters are a consequence of the differences in hydrogen and deuterium zero-point energy. The DFT calculations further reveal that there are two competitive pathways, one involves direct $\mathrm{H}$ hopping between the $\mathrm{O}_{\mathrm{b}}$ sites, and the other, two-step mechanism, involves a hop from the $\mathrm{O}_{\mathrm{b}}$ to in-plane oxygen followed by a hop from the in-plane $\mathrm{O}$ to the next $\mathrm{O}_{\mathrm{b}}$ (Fig. 17).

p0455 The situation changes completely in the presence of water adsorbed on the $\mathrm{Ti}_{5 \mathrm{c}}$ rows, which represents a more complicated diffusion process, molecule-mediated diffusion. Here, the $\mathrm{HO}_{\mathrm{b}}$ hydrogen moves from one $\mathrm{O}_{\mathrm{b}}$ row to another. The mechanistic understanding reveals that the $\mathrm{HO}_{\mathrm{b}}$ hydrogen is not simply moved from one row to another, but is incorporated into water molecule, while a different hydrogen is left behind as illustrated in Fig. $18{ }^{35}$ This scenario is only observed when the coverage is increased to the point where all $V_{O}$ s are reacted away and converted to hydroxyls (Reaction 1). Under such conditions, hydrogen starts diffusing primarily along the cross-row direction. To illustrate the mechanism, let us start with a pair of $\mathrm{HO}_{\mathrm{b}}$ (formed via water dissociation on a $V_{O}$ site, see Fig. 8) and water bound on the $\mathrm{Ti}_{5 \mathrm{c}}$ (we select $\mathrm{D}_{2} \mathrm{O}$ for clarity). The first step involves diffusion of $\mathrm{D}_{2} \mathrm{O}$ along the $\mathrm{Ti}_{5 \mathrm{c}}$ row (Fig. $18 \mathrm{~A} \rightarrow \mathrm{B}$ ); the second step is the $\mathrm{D}_{2} \mathrm{O}$ dissociation to a pair of hydroxyls (Fig. $18 \mathrm{~B} \rightarrow \mathrm{C}$ ) according to the equation:
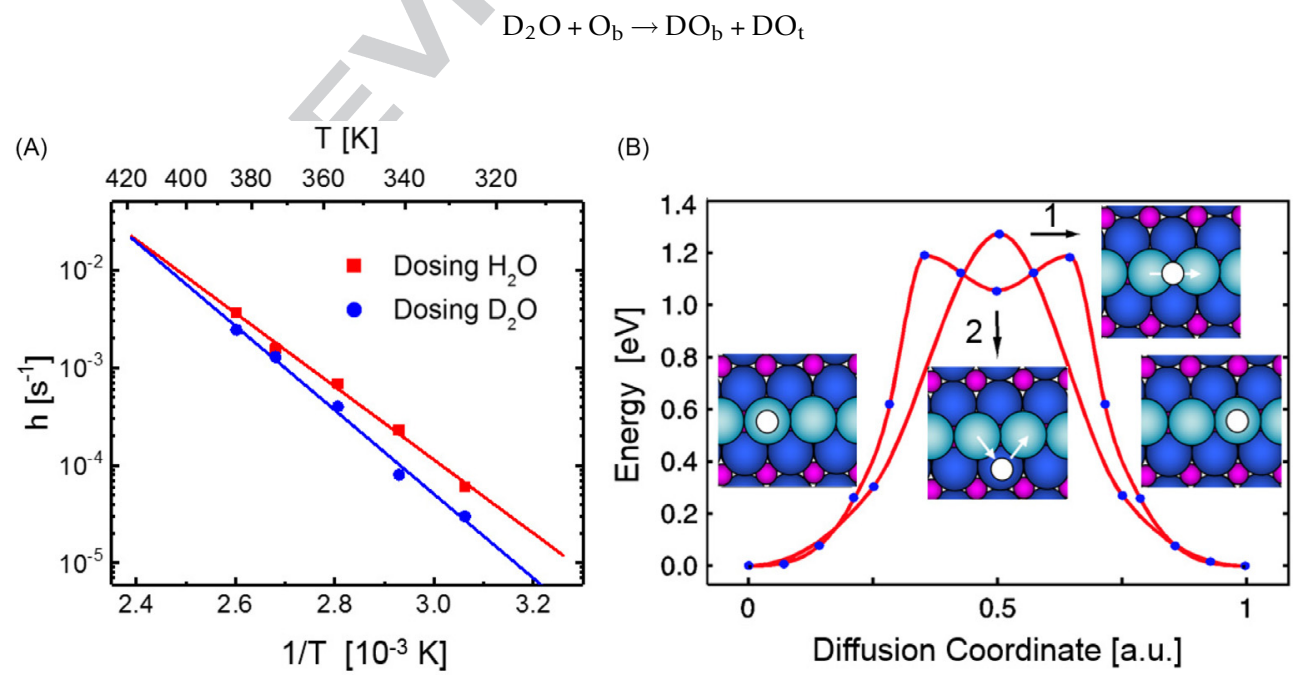

Fig. 17 Intrinsic $\mathrm{HO}_{b}$ hydrogen diffusion along the $\mathrm{O}_{b}$ rows on $\mathrm{TiO}_{2}(110)$ as illustrated in Fig. 8. (A) Arrhenius plot of the $\mathrm{HO}_{b}$ hydrogen and $\mathrm{DO}_{\mathrm{b}}$ deuterium hopping rates, $h$. (B) Two competitive pathways determined from DFT calculations: Path 1 involves a direct hydrogen hopping between the $0_{b}$ sites. Path 2 involves two steps, hop from $\mathrm{O}_{\mathrm{b}}$ to in-plane 0 atom and hop from in plane 0 to next $\mathrm{O}_{\mathrm{b}}$. Adapted with permission from Li, S.-C.; Zhang, Z.; Sheppard, D.; Kay, B. D.; White, J. M.; Du, Y.; Lyubinetsky, I.; Henkelman, G.; Dohnalek, Z. Intrinsic Diffusion of Hydrogen on Rutile $\mathrm{TiO}_{2}(110)$. J. Am. Chem. Soc. 2008, 130, 9080-9088. 


\section{IFCC: 12844}

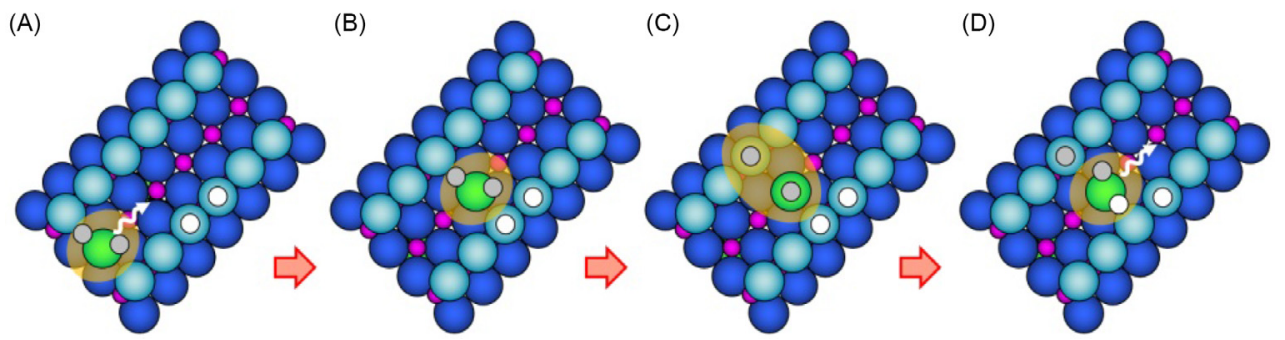

Fig. 18 Schematic view of the cross-row transport of bridging hydroxyl hydrogen mediated by diffusing $\mathrm{Ti}_{5 \mathrm{c}}$-bound water molecule on $\mathrm{TiO}_{2}(110)$ surface. Green ball: water oxygen, gray ball: deuterium, white ball: hydrogen.

Here, the $\mathrm{DO}_{\mathrm{t}}$ signifies terminal hydroxyl bound on the $\mathrm{Ti}_{5 \mathrm{c}}$ row and $\mathrm{DO}_{\mathrm{b}}$ located on the $\mathrm{O}_{\mathrm{b}}$ row neighboring the one with the $\mathrm{HO}_{\mathrm{b}}$ pair; the third step is the hydroxyl recombination leading back to water (Fig. $18 \mathrm{C} \rightarrow \mathrm{d}$ ). This step can involve the original $\mathrm{DO}_{\mathrm{t}}$ and $\mathrm{DO}_{\mathrm{b}}$ (reverse Reaction 6) or $\mathrm{DO}_{\mathrm{t}}$ and one of the $\mathrm{HO}_{\mathrm{b}} \mathrm{s}$ :

$$
\mathrm{DO}_{\mathrm{t}}+\mathrm{HO}_{\mathrm{b}} \rightarrow \mathrm{HDO}+\mathrm{O}_{\mathrm{b}}
$$

p0465 p0470 with the $\mathrm{O}_{a}$ yields two terminal hydroxyls:

$$
\mathrm{H}_{2} \mathrm{O}+\mathrm{O}_{\mathrm{a}} \rightarrow 2 \mathrm{HO}_{\mathrm{t}}
$$

p0475 Upon recombination of the two $\mathrm{HO}_{t}$ s to water, one of the two oxygen atoms can be utilized. When the original $\mathrm{O}_{a}$ is incorporated, the oxygen atom from the molecule is left behind on the surface, displaced by one site along the $\mathrm{Ti}_{5 \mathrm{c}}$ row.

p0480 Since surface reactions are an integral part of the water-mediated diffusion examples shown earlier, these processes also represent simple examples of surface reactions. Further examples are presented in the subsequent sections that deal with the formation of new surface intermediates and more complex reaction schemes.

\section{s0100 Formation of Surface Intermediates}

p0485 In this section, we provide two examples that illustrate the formation of new surface intermediates. In the first example, we show how surface defects can participate in such a process, and in the second example, we show the reaction of two adsorbed surface species.

p0490 Fig. 19 shows an example of the conversion of a Ti-bound hydroxyoxy, $\mathrm{O}_{\mathrm{b}}-\left(\mathrm{CH}_{2}\right)_{3}-\mathrm{OH}$ or a dioxo species, $\mathrm{O}_{\mathrm{b}}-\left(\mathrm{CH}_{2}\right)_{3}-\mathrm{O}_{\mathrm{Ti}}$, to a new dioxo intermediate, $\mathrm{O}_{\mathrm{b}}-\left(\mathrm{CH}_{2}\right)_{3}-\mathrm{O}_{\mathrm{b}}$, that is bound to two neighboring $\mathrm{O}_{\mathrm{b}}$ sites on rutile $\mathrm{TiO}_{2}(110){ }^{33}$ The example in Fig. 19 illustrates this for the $\mathrm{O}_{\mathrm{b}}-\left(\mathrm{CH}_{2}\right)_{3}-\mathrm{O}_{\mathrm{Ti}}$ species, which is formed as a result of the dissociation of 1,3-propanediol on the $\mathrm{V}_{\mathrm{O}}$ defect site and deprotonation of the second, Ti-bound, hydroxyl group:

$$
\begin{gathered}
\mathrm{HO}-\left(\mathrm{CH}_{2}\right)_{3}-\mathrm{OH}+\mathrm{V}_{\mathrm{O}}+\mathrm{O}_{\mathrm{b}} \rightarrow \mathrm{O}_{\mathrm{b}}-\left(\mathrm{CH}_{2}\right)_{3}-\mathrm{OH}+\mathrm{HO}_{\mathrm{b}} \\
\mathrm{O}_{\mathrm{b}}-\left(\mathrm{CH}_{2}\right)_{3}-\mathrm{OH}+\mathrm{O}_{\mathrm{b}} \rightleftarrows \mathrm{O}_{\mathrm{b}}-\left(\mathrm{CH}_{2}\right)_{3}-\mathrm{O}_{\mathrm{Ti}}+\mathrm{HO}_{\mathrm{b}}
\end{gathered}
$$

p0495 These reactions parallel those for 1,2-ethanediol (Reactions 4 and 5) illustrated above.

p0500 The $\mathrm{HO}_{\mathrm{b}}$ species formed in this sequence are mobile at the imaging temperature of $460 \mathrm{~K}$ and diffuse away from the vicinity of the $\mathrm{O}_{\mathrm{b}}-\left(\mathrm{CH}_{2}\right)_{3}-\mathrm{O}_{\mathrm{Ti}}$ species. In addition, prior studies also show that the $\mathrm{V}_{\mathrm{O}}$ defects are mobile at $460 \mathrm{~K}$, which is critical for the $\mathrm{O}_{\mathrm{b}}-\left(\mathrm{CH}_{2}\right)_{3}-\mathrm{O}_{\mathrm{Ti}}$ changes observed from Fig. 19A to B leading to the $\mathrm{I}_{\mathrm{HT}}$ intermediate. The mechanism that was put forward is shown in the schematics in Fig. 19C-E. In the first step, $\mathrm{V}_{\mathrm{O}}$ diffuses toward the $\mathrm{O}_{\mathrm{b}}-\left(\mathrm{CH}_{2}\right)_{3}-\mathrm{O}_{\mathrm{Ti}}$ species (Fig. 19C). In the second step, the $\mathrm{O}_{\mathrm{b}}-\left(\mathrm{CH}_{2}\right)_{3}-\mathrm{O}_{\mathrm{Ti}}$ rotates about the $\mathrm{O}_{\mathrm{b}}$ anchor into the empty $\mathrm{O}_{\mathrm{b}}$ site created by the diffusing $\mathrm{V}_{\mathrm{O}}$ (Fig. 19D). This results in the formation of a new dioxo intermediate that is bound to two neighboring $\mathrm{O}_{\mathrm{b}}$ sites (Fig. 19D). This process can be summarized by the following reaction:

$$
\mathrm{O}_{\mathrm{b}}-\left(\mathrm{CH}_{2}\right)_{3}-\mathrm{O}_{\mathrm{Ti}}+\mathrm{V}_{\mathrm{O}} \rightarrow \mathrm{O}_{\mathrm{b}}-\left(\mathrm{CH}_{2}\right)_{3}-\mathrm{O}_{\mathrm{b}}
$$

p0505 Similar $\mathrm{V}_{\mathrm{O}}$-assisted mechanism was also concluded for the diffusion of $\mathrm{O}_{\mathrm{b}}$-bound alkoxy species along the $\mathrm{O}_{\mathrm{b}}$ rows. ${ }^{37}$

p0510 Interestingly, the same $\mathrm{O}_{\mathrm{b}}-\left(\mathrm{CH}_{2}\right)_{3}-\mathrm{O}_{\mathrm{Ti}}$ intermediate formed by the Reaction 9 can also be created by the coupling reaction of two adsorbed formaldehyde, $\mathrm{HCHO}$, molecules. ${ }^{38}$ In the experiment shown in Fig. 20, the same area was followed, as a function of 


\section{IFCC: 12844}

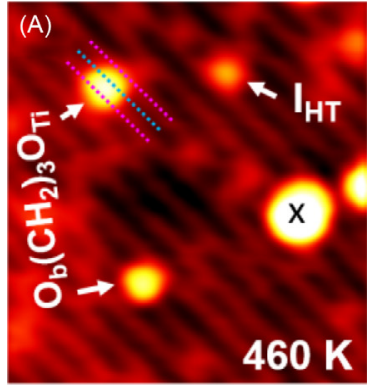

(C)

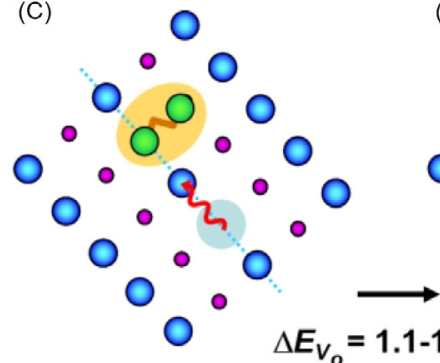

(D)
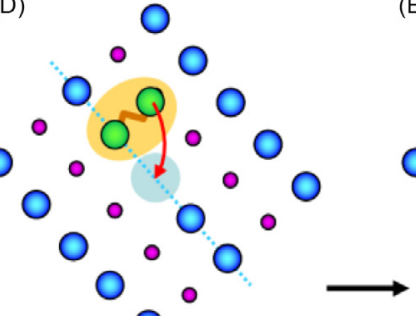

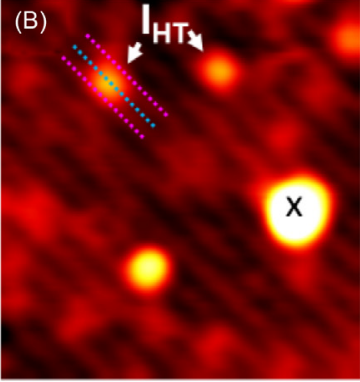

$(\mathrm{E})$

$\Delta E_{r o t}=1.46 \mathrm{eV}$

Fig. 19 Time-lapse sequence of STM images of the same area on $\mathrm{TiO}_{2}(110)$ obtained at $460 \mathrm{~K}$ : (A) surface after 1,3-propanediol adsorption, dissociation in $\mathrm{V}_{0}$, and deprotonation (Reactions 9 and 10). (B) same area after an additional 6 min of imaging leading to the formation of hightemperature intermediate, $\mathrm{I}_{\mathrm{HT}}$. The large $\mathrm{TiO}_{x}$ cluster labeled with $\times$ was used to track the same area at high temperatures. (C-E) Proposed identity and mechanism of the formation for the $I_{H T}$ intermediate. Adapted with permission from Acharya, D. P.; Yoon, Y.; Li, Z.; Zhang, Z.; Lin, X.; Mu, R.; Chen, L.; Kay, B. D.; Rousseau, R.; Dohnalek, Z. Site-Specific Imaging of Elemental Steps in Dehydration of Diols on $\mathrm{TiO}_{2}(110)$. ACS Nano 2013, 7, 10414-10423.
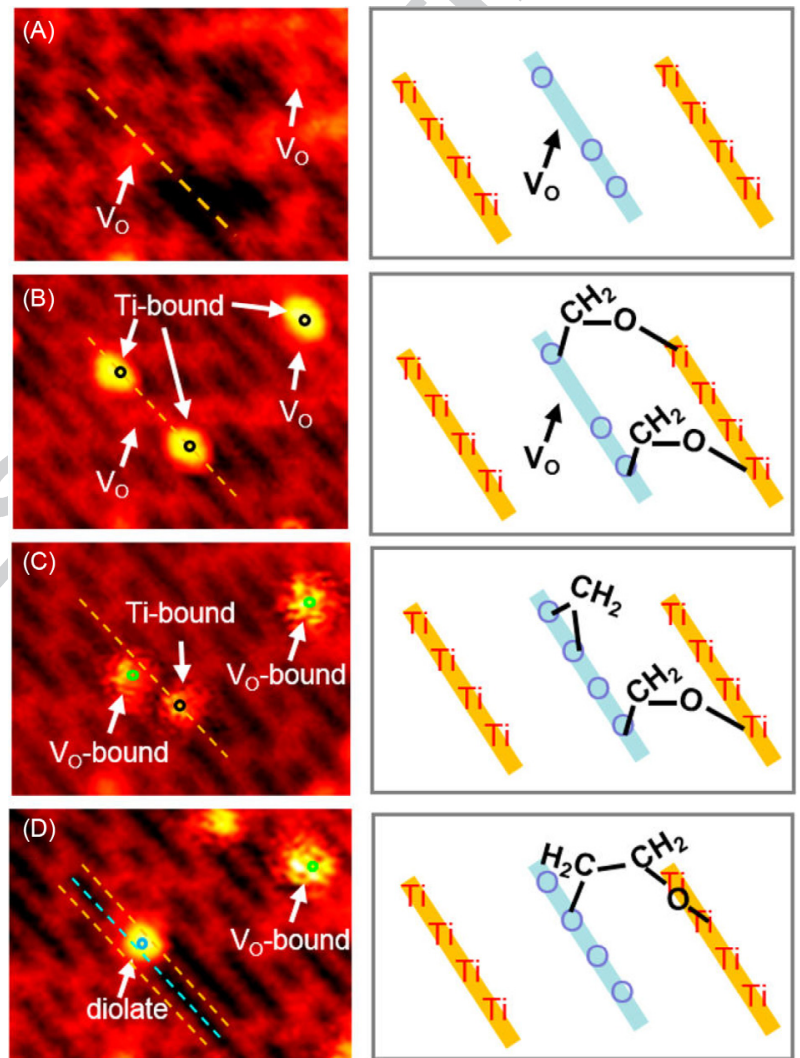

Fig. 20 STM images obtained from the same area of reduced $\mathrm{TiO}_{2}(110)$ at different temperatures, revealing the formation of dioxo $\mathrm{O}_{\mathrm{b}}-\left(\mathrm{CH}_{2}\right)_{2}-0_{\mathrm{Ti}}$ species via a coupling reaction of the Ti-bound formaldehyde and the $\mathrm{V}_{0}$-bound formaldehyde. (A) Clean surface imaged at $75 \mathrm{~K}$, (B) surface imaged at $75 \mathrm{~K}$ after dosing $0.02 \mathrm{ML}$ of formaldehyde at $75 \mathrm{~K}$, (C) surface imaged at $145 \mathrm{~K}$, and (D) surface imaged at $170 \mathrm{~K}$. Dotted lines mark the position of $\mathrm{Ti}_{5 \mathrm{c}}$ rows (orange) and $\mathrm{O}_{\mathrm{b}}$ row (blue). Reproduced with permission from Zhu, K.; Xia, Y.; Tang, M.; Wang, Z.-T.; Jan, B.; Lyubinetsky, I.; Ge, Q.; Dohnalek, Z.; Park, K. T.; Zhang, Z. Tracking Site-Specific C-C Coupling of Formaldehyde Molecules on Rutile $\mathrm{TiO}_{2}(110)$. J. Phys. Chem. C 2015, 119, 14267-14272. 
increasing temperature. This experimentally extremely challenging method enables imaging of the processes that happened at different temperatures. Here several formaldehyde molecules are imaged from their initial adsorption, to the onset of diffusion, and to the formation of new intermediates, and ultimately to the $\mathrm{C}-\mathrm{C}$ coupling reaction. Starting with the image of the clean $\mathrm{TiO}_{2}(110)$ at $75 \mathrm{~K}$ (Fig. 20A), a HCHO dose leads to three formaldehyde molecules adsorbed on the $\mathrm{Ti}_{5 \mathrm{c}}$ rows (Fig. 20B). Subsequently, the diffusion of two formaldehyde molecules at $145 \mathrm{~K}$ leads to their adsorption on the preferred $\mathrm{V}_{\mathrm{O}}$ sites (Fig. 20C). Ultimately, further diffusion of $\mathrm{Ti}_{5 \mathrm{c}}$-bound $\mathrm{HCHO}$ leads to an encounter with the $\mathrm{V}_{\mathrm{O}}$-bound formaldehyde and coupling reaction that yields the diolate, $\mathrm{O}_{\mathrm{b}}-\left(\mathrm{CH}_{2}\right)_{2}-\mathrm{O}_{\mathrm{Ti}}$, intermediate as shown in Fig. 20D.

\section{s0105 Imaging Complex Reactions}

p0515 Armed with the detailed understanding of elemental reaction steps for each adsorbate and arsenal of approaches to characterize each species (see Section "Molecular Adsorption"), STM can be utilized to follow complex reactions between different molecules. Often, many reaction steps occur concurrently making it difficult to follow what is happening with each individual species.

p0520 Such a complex reaction mechanism is illustrated for the reactions of molecular oxygen with water on $\mathrm{TiO}_{2}(110) .{ }^{39}$ In the mechanism water fulfills multiple roles: it serves as a reactant, product, and as a catalyst facilitating the diffusion of other species. As shown in separate experiments, water and oxygen can dissociate on $\mathrm{TiO}_{2}(110)$ via different dissociation pathways ${ }^{13,14,40}$ :

$$
\begin{gathered}
\mathrm{H}_{2} \mathrm{O}+\mathrm{V}_{\mathrm{O}}+\mathrm{O}_{\mathrm{b}} \rightarrow 2 \mathrm{OH}_{\mathrm{b}} \\
\mathrm{O}_{2}+\mathrm{V}_{\mathrm{O}} \rightarrow \mathrm{O}_{\mathrm{b}}+\mathrm{O}_{\mathrm{a}} \\
\mathrm{O}_{2} \rightarrow 2 \mathrm{O}_{\mathrm{a}}
\end{gathered}
$$

p0525 The oxygen adatom, $\mathrm{O}_{\mathrm{a}}$, and bridging hydroxyl, $\mathrm{OH}_{\mathrm{b}}$, intermediates can be identified using their adsorption sites, symmetry and brightness as indicated in Fig. $21 \mathrm{~A}$ and $\mathrm{B}$. The reaction between $\mathrm{OH}_{\mathrm{b}}$ and $\mathrm{O}_{2}$ further leads to hydroperoxo, $\mathrm{HO}_{2}$, intermediate (Fig. 21B) that was also identified in separate studies ${ }^{41}$ :

$$
\mathrm{OH}_{\mathrm{b}}+\mathrm{O}_{2} \rightarrow \mathrm{O}_{\mathrm{b}}+\mathrm{HO}_{2}
$$

p0530 Further, terminal hydroxyl intermediates (Fig. 21B) were shown to form via reaction of oxygen adatoms near the bridging hydroxyls:

$$
\mathrm{OH}_{\mathrm{b}}+\mathrm{O}_{\mathrm{a}} \rightarrow \mathrm{OH}_{\mathrm{t}}+\mathrm{O}_{\mathrm{b}}
$$

In the absence of $\mathrm{Ti}_{5 \mathrm{c}}$-bound water, all the above-mentioned intermediates are immobile, and the surface remains static. A small additional dose of $\mathrm{O}_{2}$ should lead to the formation of additional intermediates. Contrary to this expectation, it leads to complete disappearance of $\mathrm{V}_{\mathrm{O}}, \mathrm{O}_{\mathrm{a}}, \mathrm{HO}_{t}$, and $\mathrm{HO}_{2}$ species as shown in Fig. 21C. This abrupt change is a result of water formation via reactions between the neighboring intermediates:

$$
\begin{gathered}
\mathrm{OH}_{\mathrm{b}}+\mathrm{HO}_{2} \rightarrow \mathrm{O}_{\mathrm{b}}+\mathrm{O}_{\mathrm{a}}+\mathrm{H}_{2} \mathrm{O} \\
\mathrm{OH}_{\mathrm{b}}+\mathrm{OH}_{\mathrm{t}} \rightarrow \mathrm{O}_{\mathrm{b}}+\mathrm{H}_{2} \mathrm{O} \\
2 \mathrm{OH}_{\mathrm{t}} \rightarrow \mathrm{O}_{\mathrm{a}}+\mathrm{H}_{2} \mathrm{O}
\end{gathered}
$$
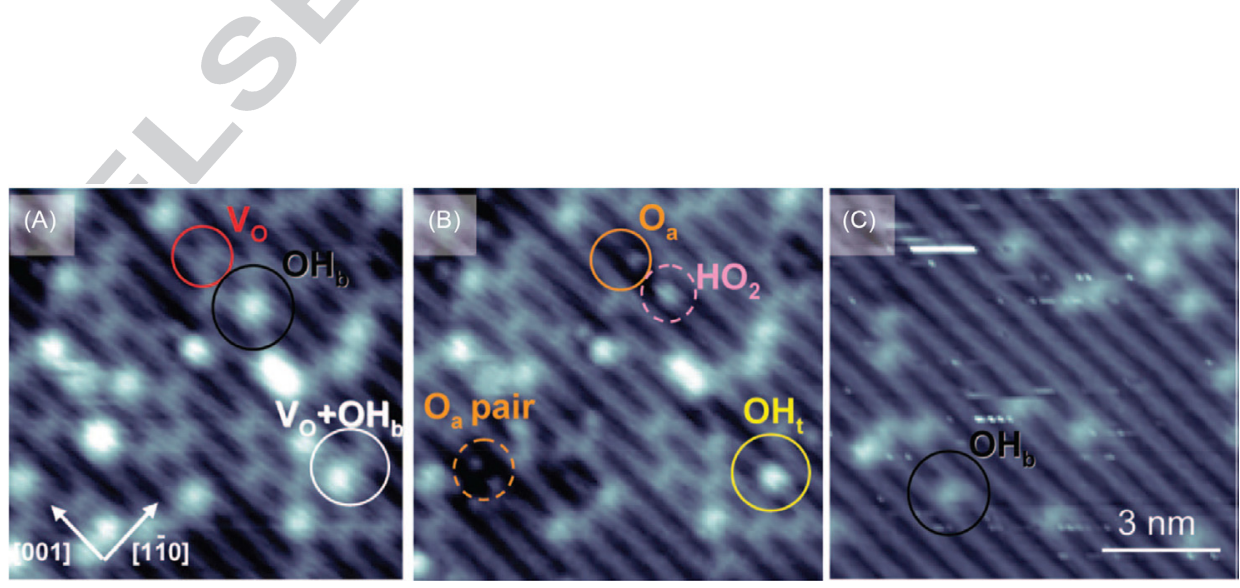

Fig. 21 STM images of the same area $\left(10 \times 10 \mathrm{~nm}^{2}\right)$ on a partially hydroxylated $\mathrm{TiO}_{2}(110)$ surface with $0.061 \mathrm{ML}$ of $\mathrm{V}_{0}$ 's and $0.043 \mathrm{ML}$ of $\mathrm{HO}$,'s. (A) Before and (B) after $\mathrm{O}_{2}$ exposures of $5.6 \times 10^{15} \mathrm{O}_{2} / \mathrm{cm}^{2}$. (C) Same area after an additional dose of $2.4 \times 10^{15} \mathrm{O}_{2} / \mathrm{cm}^{2}$ (cumulative dose of $8.0 \times 10^{15}$ $\mathrm{O}_{2} / \mathrm{cm}^{2}$ ). Reproduced with permission from Zhang, Z.; Du, Y.; Petrik, N. G.; Kimmel, G. A.; Lyubinetsky, I.; Dohnalek, Z. Water as a Catalyst: Imaging Reactions of $\mathrm{O}_{2}$ with Partially and Fully Hydroxylated $\mathrm{TiO}_{2}(110)$ Surfaces. J. Phys. Chem. C 2009, 113, 1908-1916. 


\section{IFCC: 12844}

As demonstrated earlier (Section "Adsorbate Motion"), water facilitates diffusion of $\mathrm{HO}_{b}$ and $\mathrm{O}_{\mathrm{a}}$ species. This in turns brings the species together, and the reactions above accelerate. Ultimately, the amount of initial $\mathrm{V}_{\mathrm{O}}, \mathrm{O}_{2}$, and $\mathrm{H}_{2} \mathrm{O}$ reagents determines the endpoint of the reaction. Here (Fig. 21C), besides desorbing $\mathrm{H}_{2} \mathrm{O}$, it is $\mathrm{HO}_{\mathrm{b}}$ that remains on the surface.

\section{s0110 Future Directions and Challenges}

p0545 We would like to conclude this tutorial with few examples that hint us about the future of single molecule reaction imaging. This is an exciting area with bright future that provides a wealth of information that cannot be obtained otherwise. The majority of examples given in the previous sections involved STM imaging under clean ultrahigh vacuum conditions. Hence, taking advantage of other imaging techniques such as AFM, combining STM with other spectroscopy methods to enhance its capabilities, and carrying out studies at high pressures and in condensed phase are clear frontier areas to be explored. The sections below provide few examples that illustrate progress in these areas.

\section{s0115 High Pressure and Condensed Phase Studies}

p0550 The development and utility of the reactorSTM for high-pressure studies has already been discussed (Section "Scanning Tunneling Microscopy"). While adsorbate-induced changes in the catalyst structure can be followed relatively easily, studies of adsorbates, isolated molecules in particular, become very difficult, even more so in the liquid phase. Additionally, small amounts of strongly bound contaminants/adsorbates from the environment can alter the surface structure, and their effect has to be considered under realistic reaction conditions.

p0555 An example highlighting such effects is illustrated for rutile $\mathrm{TiO}_{2}(110)$ when exposed to air and liquid water. Here, the small amount of $\mathrm{CO}_{2}$ (binds weakly on $\mathrm{TiO}_{2}(110)^{42}$ ) from the atmosphere or liquid water leads to the formation of strongly bound bicarbonate $\left(\mathrm{HCO}_{3}\right)$ species. ${ }^{43}$ This reaction is promoted by both the strong bidentate bonding of $\mathrm{HCO}_{3}$ and the nanoscale $\mathrm{H}_{2} \mathrm{O}$ film that spontaneously forms on $\mathrm{TiO}_{2}$ under ambient conditions. The formation of such ordered monolayer of $\mathrm{HCO}_{3}$ and $\mathrm{H}$ is shown in Fig. 22. The layer is stable in vacuum up to $450 \mathrm{~K}$. These results demonstrate the need for studies on well-controlled catalyst surfaces in ambient and solution environments, where competition for reactive sites plays an important role.

\section{s0120 Combined molecular beam scattering and scanning tunneling microscopy}

p0560 The power of molecular beam technology is its ability to tune the translational energy of the molecules or even prepare molecules in specific rotationally and vibrationally excited state. ${ }^{44,45}$ This allows to overcome the energy barriers for low-probability processes

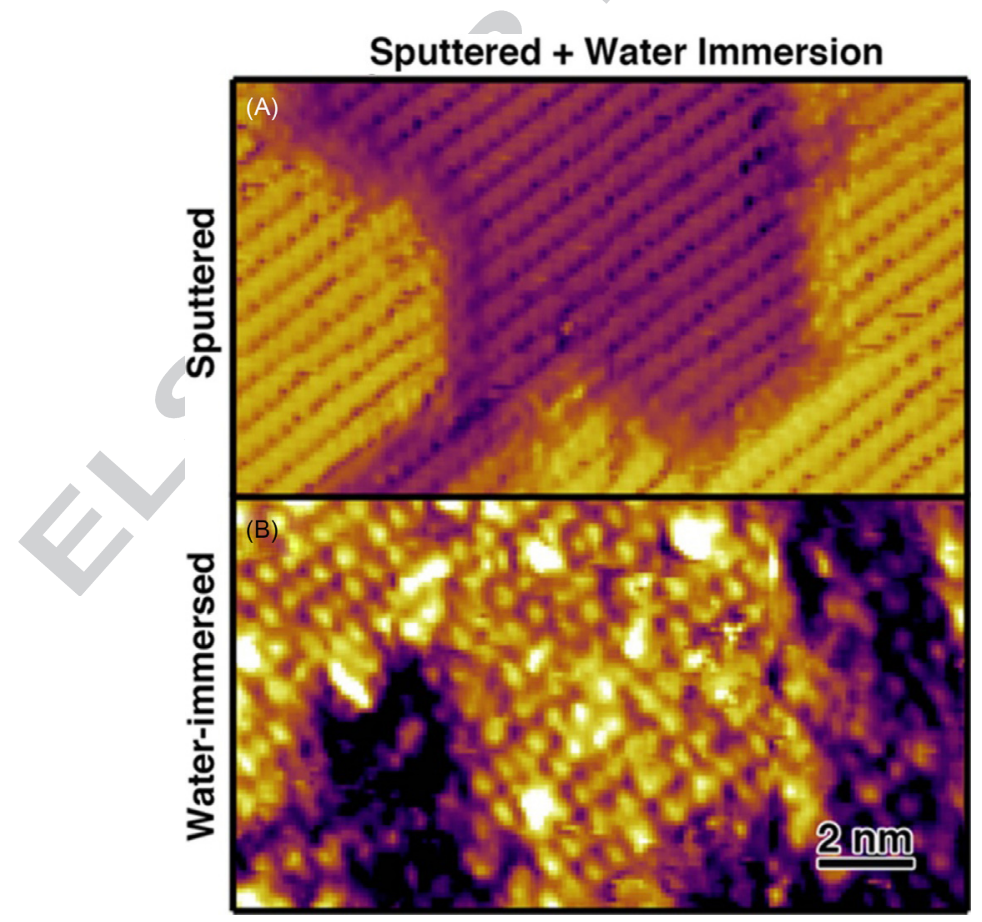

Fig. 22 STM images of $(A)$ a sputtered and annealed rutile $\mathrm{TiO}_{2}(110)$ sample that was then $(B)$ immersed in $\mathrm{H}_{2} \mathrm{O}$ for 3 min. The bicarbonate monolayer in (B) leads to periodic protrusions with a characteristic $0.60 \mathrm{~nm}$ spacing. Reprinted with permission from Song, A.; Skibinski, E. S.; DeBenedetti, W. J. I.; Ortoll-Bloch, A. G.; Hines, M. A. Nanoscale Solvation Leads to Spontaneous Formation of a Bicarbonate Monolayer on Rutile (110) under Ambient Conditions: Implications for C02 Photoreduction. J. Phys. Chem. C 2016, 120, 9326-9333. 


\section{IFCC: 12844}

(A)
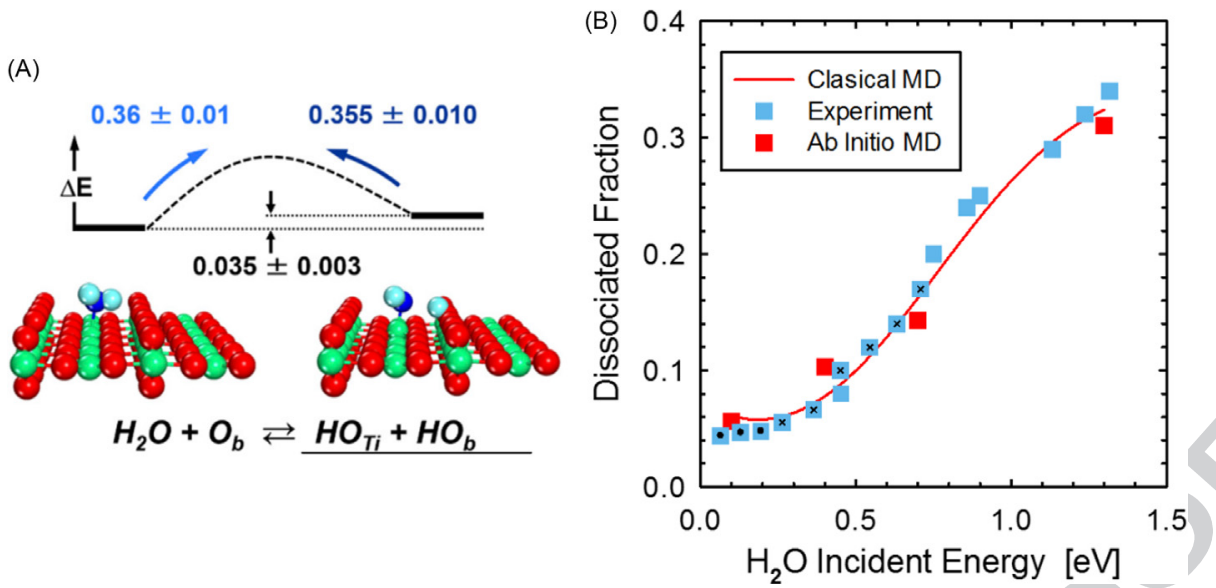

Fig. 23 (A) Relative stability and interconversion barriers for molecularly and dissociatively bound water on $\mathrm{TiO}_{2}(110)$ determined from the combined molecular beam scattering and STM imaging experiments. (B) The dissociation probability of $\mathrm{H}_{2} \mathrm{O}$ molecules impinging on the TiO ${ }_{2}(110)$ with different incident energies. Adapted with permission from Wang, Z.-T.; Wang, Y.-G.; Mu, R.; Yoon, Y.; Dahal, A.; Schenter, G. K.; Glezakou, V.-A.; Rousseau, R.; Lyubinetsky, I.; Dohnálek, Z. Probing Equilibrium of Molecular and Deprotonated Water on $\mathrm{TiO}_{2}(110)$. Proc. Natl. Acad. Sci. U. S. A. 2017, 114, $1801-1805$

and, in principle, bridge the pressure gap. By following the energy-dependent dissociation probabilities, one can probe energetics of specific reaction steps and quantify their barriers. Despite the maturity of molecular beam technology, its combination with STM proved challenging and successful executions are rather limited. ${ }^{17,46}$ Recently, the relative stability of molecular water relative to hydroxyls on $\mathrm{Ti}_{5 \mathrm{c}}$ rows of $\mathrm{TiO}_{2}(110)$ (Reaction 2) as well as their interconversion barriers have been successfully measured (Fig. 23A $)^{17}$ resolving the long-standing controversy in the literature. ${ }^{14}$

The dissociation probabilities, determined by counting the molecularly and dissociatively bound water molecules in the STM images obtained at $80 \mathrm{~K}$, are shown as a function of $\mathrm{H}_{2} \mathrm{O}$ incident energy in Fig. 23B (blue squares). The experimental data are complemented by the results of the AIMD simulations (red squares) that reveal how the electrostatic field emanating from the oxide surface leads to steering and reorientation of the molecules, activation of the $\mathrm{O}-\mathrm{H}$ bonds, and deprotonation. A classical MD model, constructed based on the AIMD results, allows for precise determination of the dissociation barrier of $0.36 \mathrm{eV}$.

\section{s0125 Adsorbate Structure Imaging with Functionalized Scanning Probes}

p0570 While atomic resolution on surfaces can nowadays be obtained routinely, the atomic resolution within the adsorbed species has been achieved only recently. ${ }^{12,47}$ The key to this advancement has been the tip functionalization. Typically, this is achieved by picking up a single $\mathrm{CO}$ molecule with the tip. This has been first accomplished with CO-functionalized AFM tips that can produce high-resolution images that closely resemble the structure of the adsorbed molecule. ${ }^{47}$ We have already discussed the IETS imaging with CO functionalized STM tips (see Section "Molecular Adsorption") that was developed later. ${ }^{31}$ For the CO-functionalized AFM tips, the atomic features only become visible when working at small tip-sample distances in the regime of Pauli repulsion between the $\mathrm{CO}$ molecule at the tip and the imaged molecule on the surface. While first demonstrated for pentacene molecules, ${ }^{47}$ the most striking example of a direct identification of the structure of more than one hundred asphaltene molecules in the mixture is illustrated in Fig. 24 (Ref. 48). The asphaltenes are the solid component of crude oil and pose an exceptional challenge for structure analysis. This study demonstrated that many different molecules can be screened by high-resolution scanning probe microscopy in a single preparation without going through a lengthy chemical synthesis, purification, and characterization for each one of them beforehand.

\section{s0130 Combining Scanning Probe Techniques with Vibrational Spectroscopies}

p0575 Following surface reactions with both topographic and chemical information at the molecular level represents an ultimate challenge for imaging techniques. While IETS (see Section "Molecular Adsorption") provides some vibrational information, it does not reveal the unique vibrational fingerprint of the molecule and the experiments require liquid helium temperatures. Raman spectroscopy and IR spectroscopy can yield a complete vibrational signature of the molecules. However, their spatial resolution is limited by the diffraction limit (hundreds of nanometers). In recent developments, Raman and IR are being combined with SPM to obtain best of both worlds, vibrational spectra of molecules with a typical spatial resolution comparable to the radius of the tip $(\sim 10 \mathrm{~nm}) .{ }^{49-53}$ 


\section{IFCC: 12844}
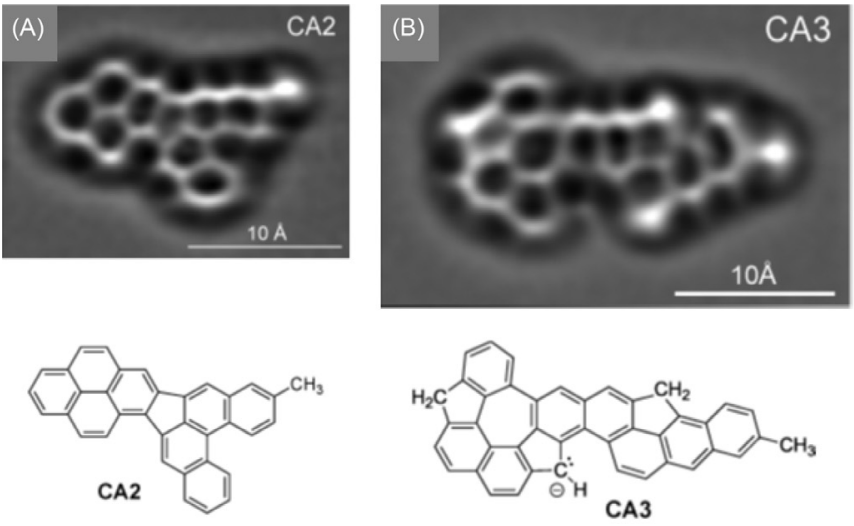

CA3
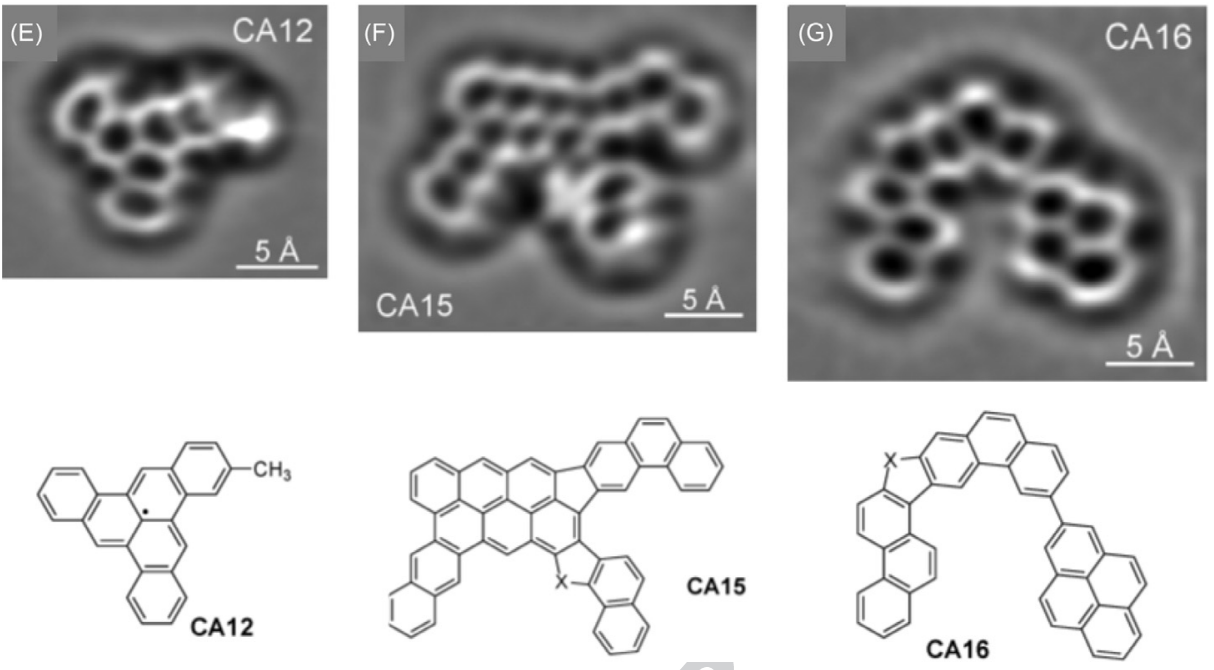
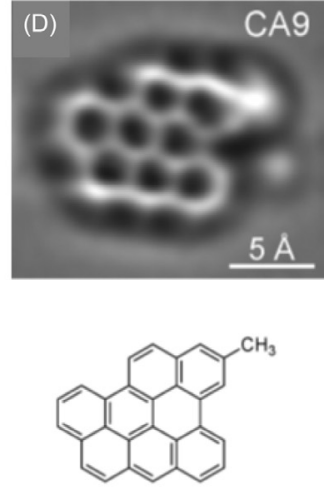

CA9
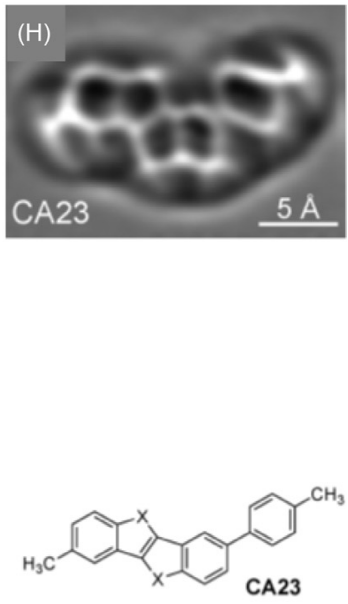

Fig. 24 Laplace-filtered AFM images of selected coal-derived asphaltenes with their derived structure. Adapted with permission from Schuler, B.; Meyer, G.; Peña, D.; Mullins, 0. C.; Gross, L., Unraveling the Molecular Structures of Asphaltenes by Atomic Force Microscopy. J. Am. Chem. Soc. 2015 137, 9870-9876.

Tip-enhanced Raman spectroscopy (TERS) utilizes the localized surface plasmons of the noble metal tip to focus the light at its apex, which enhances the weak scattered Raman signal (Fig. 25A). The advantage of TERS is that it can operate both in ultrahigh vacuum and under high pressures. Using ultrahigh-vacuum TERS, Zhang et al. conducted the chemical imaging of single $\mathrm{H}_{2}$ TBPP molecule on $\operatorname{Ag}(111) .{ }^{54}$ The characteristic four-lobed pattern of an $\mathrm{H}_{2}$ TBPP molecule is discernible in the TERS mapping (Fig. 25D). This is because the TERS peak intensities (Fig. 25C) acquired on the molecular lobe are stronger than those in the center. Their work pushed the spatial resolution of TERS to a surprising1surprising $1 \mathrm{~nm}$, which is an order of magnitude smaller than the radius of the tip.

p0585 The success of the TERS shows the great potential of imaging catalytic reactions at the molecular scale. Both experimental development and theoretical understanding of TERS experienced a rapid growth in last several years. Currently, most of the TERS studies have been done using gap mode, utilizing plasmonic metal tip and plasmonic metal substrates, to maximize the enhancement of Raman signal. The studies on nonmetal substrates are still very limited. ${ }^{55}$

\section{Acknowledgments}

ZZ acknowledges supported by the National Science Foundation under Grant CHE-1609608. ZD acknowledges support of the US Q1 Department of Energy, Office of Basic Energy Sciences, Division of Chemical Sciences, Geosciences \& Biosciences. Pacific Northwest National Laboratory (PNNL) is a multiprogram national laboratory operated for DOE by Battelle. 


\section{IFCC: 12844}

(A)

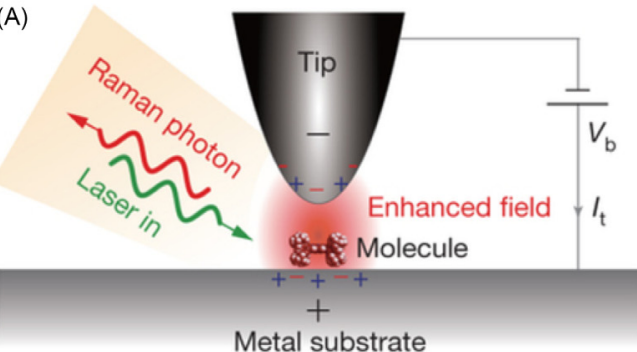

(B)

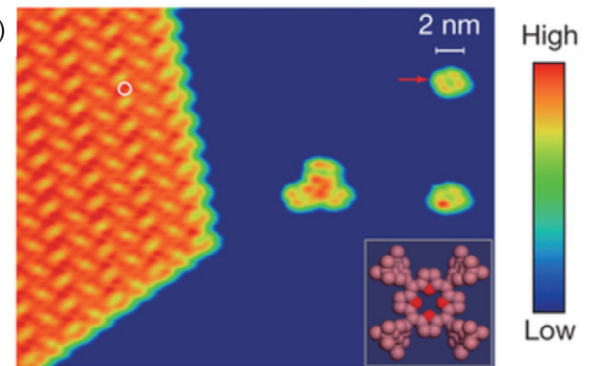

(C)

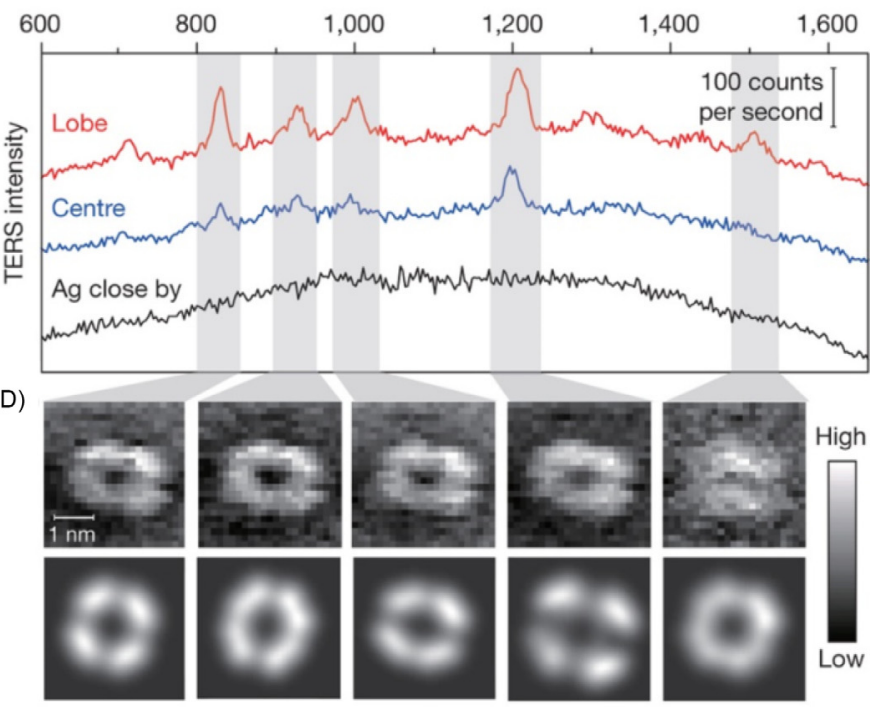

Fig. 25 (A) Schematic tunneling-controlled TERS in a confocal-type side-illumination configuration. (B) STM image (1.5 V, $30 \mathrm{pA}, 35 \mathrm{~nm} \times 27 \mathrm{~nm})$ of isolated meso-tetrakis(3,5-di-tertiarybutylphenyl)-porphyrin $\left(\mathrm{H}_{2} \mathrm{TBPP}\right)$ molecules on $\mathrm{Ag}(111)$. The inset shows the chemical structure of $\mathrm{H}_{2} \mathrm{TBPP}$. (C) Representative single molecule TERS spectra on the lobe ( $r e d)$ and center (blue) of a flat-lying $\mathrm{H}_{2} \mathrm{TBPP}$ molecule on $\mathrm{Ag}(111)$. The TERS spectrum on the bare $\mathrm{Ag}$ about $1 \mathrm{~nm}$ away from the molecule is also shown, in black (120 mV, $1 \mathrm{nA}, 3 \mathrm{~s})$. (D) The top panels show experimental TERS mapping of a single molecule for different Raman peaks $(23 \times 23, \sim 0.16 \mathrm{~nm}$ per pixel), processed from all individual TERS spectra acquired at each pixel (120 mV $1 \mathrm{nA}, 0.3 \mathrm{~s}$; image size: $3.6 \times 3.6 \mathrm{~nm}^{2}$ ). The bottom panels show the theoretical simulation of the TERS mapping. Reproduced with permission from Zhang, R.; Zhang, Y.; Dong, Z. C.; Jiang, S.; Zhang, C.; Chen, L. G.; Zhang, L.; Liao, Y.; Aizpurua, J.; Luo, Y.; Yang, J. L.; Hou, J. G. Chemical Mapping of a Single Molecule by Plasmon-Enhanced Raman scattering. Nature 2013, 498, 82-86.

\section{References}

1. Binnig, G.: Rohrer, H. Gerber, C. Weibel, E. Tunneling through a Controllable Vacuum gap. Appl. Phys. Lett. 1982, 40, 178-180.

2. Binnig, G.; Rohrer, H.; Gerber, C.; Weibel, E. $7 \times 7$ Reconstruction on Si(111) Resolved in Real Space. Phys. Rev. Lett. 1983, 50, 120-123.

3. Wiesendanger, R. Scanning Probe Microscopy: Analytical Methods; Springer: Berlin/Heidelberg, 2013.

4. Stroscio, J. A.; Eigler, D. M. Atomic and Molecular Manipulation with the Scanning Tunneling Microscope. Science 1991, 254, 1319-1326.

5. Onishi, H.; Iwasawa, Y. STM Imaging of Formate Intermediates Adsorbed on a $\mathrm{TiO}_{2}(110)$ Surface. Chem. Phys. Lett. 1994, 226, 111-114.

6. Binnig, G.; Rohrer, H.; Gerber, C.; Weibel, E. Surface Studies by Scanning Tunneling Microscopy. Phys. Rev. Lett. 1982, 49, 57-61.

7. Bonnell, D. Scanning Probe Microscopy and Spectroscopy: Theory, Techniques, and Applications; Wiley: New York, 2000.

8. Rasmussen, P. B.; Hendriksen, B. L. M.; Zeiilemaker, H.; Ficke, H. G.; Frenken, J. W. M. The "Reactor STM": A Scanning Tunneling Microscope for Investigation of Catalytic Surfaces at Semi-Industrial Reaction Conditions. Rev. Sci. Instrum. 1998, 69, 3879-3884.

9. Rößler, M.; Geng, P.; Wintterlin, J. A High-Pressure Scanning Tunneling Microscope for Studying Heterogeneous Catalysis. Rev. Sci. Instrum. 2005, 76, 023705

10. Giessibl, F. J. Advances in Atomic Force Microscopy. Rev. Mod. Phys. 2003, 75, 949-983.

11. Haugstad, G. Atomic Force Microscopy: Understanding Basic Modes and Advanced Applications; Wiley: New York, 2012.

12. Gross, L. Recent Advances in Submolecular Resolution with Scanning Probe Microscopy. Nat. Chem. 2011, 3, 273-278.

13. Diebold, U. The Surface Science of Titanium Dioxide. Surf. Sci. Rep. 2003, 48, 53-229.

14. Dohnalek, Z.; Lyubinetsky, I., Rousseau, R. Thermally-Driven Processes on Rutile Ti0 2 (110)-(1 × 1): A Direct View at the Atomic Scale. Prog. Surf. Sci. 2010, 85 , 161-205.

15. Pang, C. L.; Lindsay, R.; Thornton, G. Structure of Clean and Adsorbate-Covered Single-Crystal Rutile $\mathrm{TiO}_{2}$ Surfaces. Chem. Rev. 2013, 113, 3887-3948.

16. Yates, J. T. Experimental Innovations in Surface Science: A Guide to Practical Laboratory Methods and Instruments; AIP Press: New York, 1998.

17. Wang, Z.-T.; Wang, Y.-G.; Mu, R.; Yoon, Y.; Dahal, A.; Schenter, G. K.; Glezakou, V.-A.; Rousseau, R.; Lyubinetsky, I.; Dohnálek, Z. Probing Equilibrium of Molecular and Deprotonated Water on $\mathrm{TiO}_{2}(110)$. Proc. Natl. Acad. Sci. U. S. A. 2017, 114, 1801-1805.

18. Muino, R. D.; Busnengo, H. F. Dynamics of Gas-Surface Interactions: Atomic-Level Understanding of Scattering Processes at Surfaces; Springer: Berlin Heidelberg, 2013.

19. Yang, H. J.; Minato, T.; Kawai, M.; Kim, Y. STM Investigation of CO Ordering on Pt(111): From an Isolated Molecule to High-Coverage Superstructures. J. Phys. Chem. C 2013 $117,16429-16437$

20. Zhang, Z.; Bondarchuk, 0.; Kay, B. D.; White, J. M.; Dohnalek, Z. Imaging Water Dissociation on $\mathrm{TiO}_{2}(110)$ : Evidence for Inequivalent Geminate OH Groups. J. Phys. Chem. B 2006, 110, 21840-21845.

21. Cui, X. F.: Wang, Z.; Tan, S. J.; Wang, B.; Yang, J. L.; Hou, J. G. Identifying Hydroxyls on the Ti0 2 (110)-1 × 1 Surface with Scanning Tunneling Microscopy. J. Phys. Chem. C 2009, 113, 13204-13208.

22. Stroscio, J. A.; Kaiser, W. J. Scanning Tunneling Microscopy; Elsevier Science: Amsterdam,Netherlands, 1993.

23. Minato, T.; Sainoo, Y.; Kim, Y.; Kato, H. S.; Aika, K.; Kawai, M.; Zhao, J.; Petek, H.; Huang, T.; He, W.; Wang, B.; Wang, Z.; Zhao, Y.; Yang, J. L.; Hou, J. G. The Electronic Structure of Oxygen Atom Vacancy and Hydroxyl Impurity Defects on Titanium Dioxide (110) Surface. J. Chem. Phys. 2009, 130, 124502.

24. Samori, P. Scanning Probe Microscopies beyond Imaging: Manipulation of Molecules and Nanostructures; Wiley: Weinheim, 2006

25. Acharya, D. P.; Ciobanu, C. V.; Camillone, N.; Sutter, P. Mechanism of Electron-Induced Hydrogen Desorption from Hydroxylated Rutile TiO 2 (110). J. Phys. Chem. C 2010, 114, 21510-21515

26. Wang, Z.-T.; Du, Y.; Dohnálek, Z.; Lyubinetsky, I. Direct Observation of Site-Specific Molecular Chemisorption of $\mathrm{O}_{2}$ on TiO $\mathrm{T}_{2}$ (110). J. Phys. Chem. Lett. 2010, 1, 3524-3529. 


\section{IFCC: 12844}

27. Tersoff, J.; Hamann, D. R. Theory and Application for the Scanning Tunneling Microscope. Phys. Rev. Lett. 1983, 50, 1998-2001.

28. He, Y.; Tilocca, A.; Dulub, 0.; Selloni, A.; Diebold, U. Local Ordering and Electronic Signatures of Submonolayer Water on Anatase Ti02(101). Nat. Mater. 2009, 8, 585-589.

29. Stipe, B. C.; Rezaei, M. A.; Ho, W. Single-Molecule Vibrational Spectroscopy and Microscopy. Science 1998, 280, 1732-1735.

30. Dette, C.; Pérez-Osorio, M. A.; Mangel, S.; Giustino, F.; Jung, S. J.; Kern, K. Single-Molecule Vibrational Spectroscopy of $\mathrm{H}_{2} \mathrm{O}$ on Anatase TiO 2 (101). J. Phys. Chem. C 2017 $121,1182-1187$

31. Chiang, C.-I.; Xu, C.; Han, Z.; Ho, W. Real-Space Imaging of Molecular Structure and ChemicalBonding by Single-Molecule Inelastic Tunneling Probe. Science 2014, 344, $885-888$

32. Zhang, Z.; Rousseau, R.; Gong, J.; Kay, B. D.; Dohnalek, Z. Imaging Hindered Rotations of Alkoxy Species on TiOz(110). J. Am. Chem. Soc. 2009, 131, 17926-17932.

33. Acharya, D. P.; Yoon, Y.; Li, Z.; Zhang, Z.; Lin, X.; Mu, R.; Chen, L.; Kay, B. D.; Rousseau, R.; Dohnalek, Z. Site-Specific Imaging of Elemental Steps in Dehydration of Diols on $\mathrm{TiO}_{2}(110)$. ACS Nano 2013, 7, 10414-10423

34. Li, S.-C.; Zhang, Z.; Sheppard, D.; Kay, B. D.; White, J. M.; Du, Y.; Lyubinetsky, I.; Henkelman, G.; Dohnalek, Z. Intrinsic Diffusion of Hydrogen on Rutile TiO 2 (110). J. Am. Chem. Soc. 2008, 130, 9080-9088

35. Wendt, S.; Matthiesen, J.; Schaub, R.; Vestergaard, E. K.; Laegsgaard, E.; Besenbacher, F.; Hammer, B. Formation and Splitting of Paired Hydroxyl Groups on Reduced Ti0 2 (110). Phys. Rev. Lett. 2006, 96, 066107

36. Du, Y.; Deskins, N. A.; Zhang, Z.; Dohnalek, Z.; Dupuis, M.; Lyubinetsky, I. Two Pathways for Water Interaction with Oxygen Adatoms on TiO 2 (110). Phys. Rev. Lett. 2009, 102, 096102.

37. Zhang, Z.; Rousseau, R.; Gong, J.; Li, S.-C.; Kay, B. D.; Ge, Q.; Dohnalek, Z. Vacancy-Assisted Diffusion of Alkoxy Species on Rutile TiO 2 (110). Phys. Rev. Lett. 2008, 101, 156103.

38. Zhu, K.; Xia, Y.; Tang, M.; Wang, Z.-T.; Jan, B.; Lyubinetsky, I.; Ge, Q.; Dohnalek, Z.; Park, K. T.; Zhang, Z. Tracking Site-Specific C-C Coupling of Formaldehyde Molecules on Rutile $\mathrm{TiO}_{2}(110)$. J. Phys. Chem. C 2015, 119, 14267-14272.

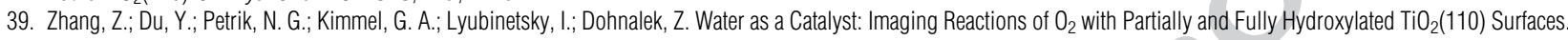
J. Phys. Chem. C 2009, 113, 1908-1916.

40. Pang, C. L.; Lindsay, R.; Thornton, G. Chemical Reactions on Rutile $\mathrm{TiO}_{2}(110)$. Chem. Soc. Rev. 2008, 37, 2328-2353.

41. Du, Y.; Deskins, N. A.; Zhang, Z.; Dohnalek, Z.; Dupuis, M.; Lyubinetsky, I. Imaging Consecutive Steps of $\mathrm{O}_{2}$ Reaction with Hydroxylated $\mathrm{TiO}_{2}(110)$ : Identification of $\mathrm{HO}_{2}$ and Terminal OH Intermediates. J. Phys. Chem. C 2009, 113, 666-671.

42. Lin, X.; Yoon, Y.; Petrik, N. G.; Li, Z.; Wang, Z.-T.; Glezakou, V.-A.; Kay, B. D.; Lyubinetsky, I.; Kimmel, G. A.; Rousseau, R.; Dohnalek, Z. Structure and Dynamics of CO ${ }_{2}$ on Rutile $\mathrm{TiO}_{2}(110)-1 \times 1$. J. Phys. Chem. C 2012, 116, 26322-26334.

43. Song, A.; Skibinski, E. S.; DeBenedetti, W. J. I.; Ortoll-Bloch, A. G.; Hines, M. A. Nanoscale Solvation Leads to Spontaneous Formation of a Bicarbonate Monolayer on Rutile (110) under Ambient Conditions: Implications for C02 Photoreduction. J. Phys. Chem. C 2016, 120, 9326-9333.

44. Zaera, F. Use of Molecular Beams for Kinetic Measurements of Chemical Reactions on Solid Surfaces. Surf. Sci. Rep. 2017, 72, 59-104.

45. Kleyn, A. W. Molecular Beams and Chemical Dynamics at Surfaces. Chem. Soc. Rev. 2003, 32, 87-95.

46. Jensen, J. A.; Yan, C.; Kummel, A. C. Energy Dependence of Abstractive Versus Dissociative Chemisorption of Fluorine Molecules on the Silicon (111)-(7 × 7) Surface. Science 1995, 267, 493-496

47. Gross, L.; Mohn, F.; Moll, N.; Liljeroth, P.; Meyer, G. The Chemical Structure of a Molecule Resolved by Atomic Force Microscopy. Science 2009, 325, 1110-1114.

48. Schuler, B.; Meyer, G.; Peña, D.; Mullins, O. C.; Gross, L. Unraveling the Molecular Structures of Asphaltenes by Atomic Force Microscopy. J. Am. Chem. Soc. 2015, 137, 9870-9876.

49. Park, K.-D.; Muller, E. A.; Kravtsov, V.: Sass, P. M.; Dreyer, J.; Atkin, J. M.; Raschke, M. B. Variable-Temperature tip-Enhanced Raman Spectroscopy of Single-Molecule Fluctuations and Dynamics. Nano Lett. 2016, 16, 479-487.

50. Jiang, N.; Chiang, N.; Madison, L. R.; Pozzi, E. A.; Wasielewski, M. R.; Seideman, T.; Ratner, M. A.; Hersam, M. C.; Schatz, G. C.; Van Duyne, R. P. Nanoscale Chemical Imaging of a Dynamic Molecular Phase Boundary with Ultrahigh Vacuum tip-Enhanced Raman Spectroscopy. Nano Lett. 2016, 16, 3898-3904.

51. Pollard, B.; Muller, E. A.; Hinrichs, K.; Raschke, M. B. Vibrational Nano-Spectroscopic Imaging Correlating Structure with Intermolecular Coupling and Dynamics. Nat. Commun. 2014, 5, 3587

52. Amenabar, I.; Poly, S.; Nuansing, W.; Hubrich, E. H.; Govyadinov, A. A.; Huth, F.; Krutokhvostov, R.; Zhang, L.; Knez, M.; Heberle, J.; Bittner, A. M.; Hillenbrand, R. Structural Analysis and Mapping of Individual Protein Complexes by Infrared Nanospectroscopy. Nat. Commun. 2013, 4, 2890.

53. Lu, F.; Jin, M.; Belkin, M. A. Tip-Enhanced Infrared Nanospectroscopy Via Molecular Expansion Force Detection. Nat Photon 2014, 8, 307-312.

54. Zhang, R.; Zhang, Y.; Dong, Z. C.; Jiang, S.; Zhang, C.; Chen, L. G.; Zhang, L.; Liao, Y.; Aizpurua, J.; Luo, Y.; Yang, J. L.; Hou, J. G. Chemical Mapping of a Single Molecule by Plasmon-Enhanced Raman Scattering. Nature 2013, 498, 82-86.

55. He, Z.; Voronine, D. V.; Sinyukov, A. M.; Liege, Z. N.; Birmingham, B.; Sokolov, A. V.; Zhang, Z.; Scully, M. O. Tip-Enhanced Raman Scattering on Bulk MoS, Substrate. IEEE J. Sel. Top. Quantum Electron. 2017, 23, 113-118. 


\section{IFCC: 12844}

\section{Non-Print Items}

\section{Abstract:}

In this article, we focus on demonstrating the utility of the scanning probe methods in the imaging of chemical reactions. We first highlight the utility of different imaging methods and highlight their strengths and weaknesses. Subsequently, we select a number of examples to illustrate different surface processes including adsorption, dissociation, diffusion and rotation of adsorbed molecules, formation of reaction intermediates, and conclude with complex reactions. In these examples, we mainly focus on the STM, which is most extensively employed as a method of choice. To limit the complexity of the article we have selected only a few systems for the discussion. In particular, elemental steps in the reactions of water alcohols, and diols on $\mathrm{TiO}_{2}(110)$ surface are utilized to illustrate the power of imaging techniques in our understanding of surface chemistry. We also provide a brief outlook on both current and future challenges in this exciting area of research.

Keywords: Adsorbate imaging; Adsorption; Atomic force microscopy; Diffusion; Elemental reaction steps; Mars van Krevelen mechanism; Reaction intermediates; Reaction mechanism; Scanning tunneling spectroscopies; Surface dynamics; Surface reactions; Titanium dioxide 